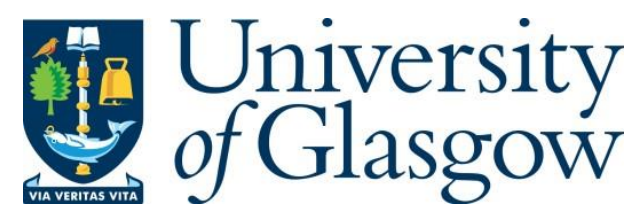

Buckley, R.M., Jardine, R.J., Kontoe, S., Parker, D. and Schroeder, F.C. (2018) Ageing and cyclic behaviour of axially loaded piles driven in chalk. Geotechnique, 68(2), pp. 146-161.

There may be differences between this version and the published version. You are advised to consult the publisher's version if you wish to cite from it.

http://eprints.gla.ac.uk/227992/

Deposited on: 18 January 2021

Enlighten - Research publications by members of the University of Glasgow

http://eprints.gla.ac.uk 


\section{Ageing and cyclic behaviour of axially loaded piles driven in chalk}

Buckley, R.M. ${ }^{1}$, roisin.buckley13@imperial.ac.uk

Jardine, R.J. ${ }^{1}$,

Kontoe, S. ${ }^{1}$,

Parker, D. ${ }^{1}$,

Schroeder, F.C. ${ }^{2}$

1. Department of Civil \& Environmental Engineering, Imperial College London, UK 2. Geotechnical Consulting Group LLP, London, UK

\section{ABSTRACT}

This paper reports a programme of static and cyclic loading tests on seven open steel tubes driven in low to medium density chalk at a well characterised test site, describing their response to driving, ageing in situ and loading under both static and cyclic conditions. Back analysis of dynamic monitoring identifies the distributions of notably low shaft resistances that develop during installation, showing that these depend strongly on the relative pile tip depth (h/R). The shaft capacities available to 'virgin' piles are shown to increase markedly after driving, following a hyperbolic trend that led to a fivefold gain after 250 days. Pre-failed piles do not follow the same trend when re-tested. Pile exhumation confirmed that driving remoulded the chalk, creating a puttified zone around the shaft. Excess pore water pressure dissipation, which is likely to have been rapid during and after driving, led to markedly lower water contents close to the shaft. Axial cyclic testing conducted around 250 days after driving led to a range of responses, from manifesting stable behaviour over 1000 cycles to failing after low numbers of cycles after developing sharp losses of static capacity. The dependence of permanent displacement on the cyclic loading parameters is explored and characterised. The experiments provide the first systematic study of which the Authors are aware into the effects of undisturbed ageing and cyclic loading on previously unfailed piles driven in chalk. Potential predictive tools may now be tested against the reported field measurements.

Keywords: chalk, cyclic loading, offshore engineering, piles, time dependence

(Main text around 5880 words) 


\section{INTRODUCTION}

Open steel piles are driven routinely for port, bridge and offshore energy projects, including large numbers of offshore wind-turbines; Doherty et al. (2011). However, their design and installation is difficult when chalk is encountered. Chalk, a highly variable soft biomicrite composed of mainly silt sized crushable $\mathrm{CaCO}_{3}$ particles, is found widespread across Northern Europe and under the North Sea, where thicknesses can exceed 1200m; Clayton et al. (2002), Mortimore (2012). While few carefully stage-loaded static load tests have been reported to prove or predict the piles' ability to carry axial loads, low shaft driving resistances (between 0 and $20 \mathrm{kPa}$ ) have been reported from dynamic driving analyses that suggest low static service capacities (Lord et al., 2002, Vijayvergiya et al., 1977). The Construction Industry Research and Information Association (CIRIA) offers design guidelines based on four pile tests that indicate widely different ultimate unit shaft resistances of 20 to $120 \mathrm{kPa}$ for low-medium and high density chalks respectively (Lord et al., 2002). These values appear remarkably low, given the intact chalk's Unconfined Compressive Strength (UCS) range of 1.25 to >12.5MPa (Bowden et al., 2002) and cone tip resistances, $\mathrm{q}_{\mathrm{c}}$ of 4 to $>50 \mathrm{MPa}$ (Power, 1982). The low static shaft capacities recommended by Lord et al. (2002) imply low shaft radial effective stresses even after full equalisation. Similar conclusions followed from Burland and French's (1990) tests on steel box piles, that could be expanded mechanically after driving. Their shaft friction capacities increased by almost $400 \%$ when the cross sectional areas were expanded by $14.3 \%$ following driving in low-medium density chalk. Stark choices have to be made when selecting design parameters that can impact significantly in projects involving potentially hundreds of large piles; Carrington et al. (2011).

Dynamic percussion damage during driving provides one explanation for low driving resistance. De-structuration and crushing of hollow calcium carbonate $\left(\mathrm{CaCO}_{3}\right)$ particles beneath the advancing pile tips produces low strength putty that spreads along the pile and limits drastically the radial effective stresses and shear resistances that can act on the shaft; Hobbs and Atkinson (1993), Lord et al. (2002). The shaft shear stresses available at any depth appear to attenuate with increasing relative distance from the pile tip, $h$, as the pile penetrates; Norrie (2015). Similar dependencies on " $h / R$ " (where $R$ is the pile radius) have been reported for clays and sands by Bond and Jardine (1991), Lehane and Jardine (1992a, 1992b), Lehane et al. (1993), Chow (1997) and Jardine et al. (2005a). Such trends were termed "friction fatigue" in clay by Heerema (1978) and for sand by Randolph et 
al. (1994) and White (2005). High-level laboratory simple shear cyclic loading and cyclic cone penetration tests (CPT) have also been found to reduce the shear stresses that intact chalk can carry to as low as $4 \mathrm{kPa}$ (Carrington et al., 2011, Diambra et al., 2014). However, large diameter offshore piles have been known to free-fall considerable distances rapidly in chalk without any hammering (Norrie, 2015); dynamic load cycling is not essential to low installation resistances.

Dynamic monitoring often shows capacity growth over driving pauses. Long term beneficial time effects on static shaft resistance have been reported in sands (see Jardine et al. (2006), Rimoy et al. (2015) or Gavin et al. (2015)) and clays, e.g. Karlsrud et al. (2014). While Lord et al. (2002) suggested that field set-up (or increase in capacity with time) also takes place with low-medium density chalk, due to pore pressure dissipation and/or internal recementing of the putty annulus around the pile, redox chemical reactions may also play a role. Vijayvergiya et al. (1977) reported an $80 \%$ increase in dynamic driving resistance over a 60 day pause in an offshore project, while Skov and Denver (1988) interpreted a 383\% increase over 13 days from static and dynamic load tests on two concrete piles driven in chalk. Lahrs and Kallias (2013) reported $50 \%$ to $60 \%$ increases in shaft resistance in chalk over four months from multiple offshore dynamic restrikes on $1.5 \mathrm{~m}$ diameter piles, but found the shaft capacity of a single pile fell over time when subjected to multiple restrikes and a static test. Re-testing pre-failed piles is often misleading; pre-failed piles often show far less set-up than equivalent "virgin" piles in sands and clays; Jardine et al. (2006), Jardine and Standing (2012), Karlsrud et al. (2014). Ciavaglia et al. (2017b) described the results of three tension tests conducted on the same $0.762 \mathrm{~m}$ diameter $4 \mathrm{~m}$ long steel piles which showed shaft resistances increasing by up to $700 \%$ in re-tests conducted over four months. Their strain gauge readings indicated four to six times higher shaft resistances applying on the lower halves of the piles, as well as a significant deleterious effect of previous lateral loading.

Foundations are often subjected to repeated or cyclic loading under a wide range of loading rates. Offshore piles sustain wind and wave loading cycles during storms, while wind-turbines impose millions of rotating blade cycles (Jardine et al., 2012). The effects of relatively slow (non-dynamic) wave load cycling can be investigated in field tests. Burland and French (1990) report that the tension capacity of their steel pile had reduced by $60 \%$ after 20 slowly applied axial cycles. However, little other guidance appears to be available regarding this potentially important factor. A range of procedures exist to address non-dynamic axial cycling for piles driven in sands and clays. Jardine et al. (2012) and Andersen et al. (2013) set out approaches involving empirical global methods, 
local (T-z) analyses based on soil element or instrumented pile tests and fully implicit numerical techniques based on advanced constitutive models. Whilst the latter provide potentially the most powerful tools, difficulties arise in full implementation, see for example Buckley (2014). There is a clear need for reliable cyclic pile tests at chalk sites, supported by high quality site characterisation, to provide benchmarks against which potential predictive procedures may be developed, assessed and calibrated.

The above design guidance shortcomings pose significant risks for the potentially thousands of offshore windturbines planned for chalk sites. Barbosa et al. (2015) and Jardine (2017) outline a Joint Industry Project (JIP) research programme that aims to improve design reliability. This paper reports one element; field tests at St Nicholas at Wade, Kent, UK, on seven $139 \mathrm{~mm}$ outside diameter steel tubular piles driven to $5.5 \mathrm{~m}$ penetrations in low-medium density chalk. These experiments investigated:

a) Dynamic resistances during driving;

b) How pile installation and testing affected the chalk surrounding the pile shaft;

c) Capacity-ageing trends for virgin piles over 8 months after installation;

d) The impact of pre-testing to failure; and

e) How multiple 'virgin" piles respond to large numbers of one-way non-dynamic axial load cycles after 8 months of ageing after driving.

\section{PILE TESTS AT ST. NICHOLAS AT WADE}

\section{GROUND CONDITIONS}

\section{Recent and previous investigations}

The experiments were conducted in a quarry close to St. Nicholas at Wade, $15 \mathrm{~km}$ west of Margate, Kent where all overburden and weathered material has been removed to expose chalk from the Margate White Chalk subgroup which comprises $98.6 \% \mathrm{CaCO}_{3}$ (Hancock, 1975). Five boreholes were advanced to a maximum $20.5 \mathrm{~m}$ depth and eleven CPTs to a depth of $17 \mathrm{~m}$ in earlier site investigation studies (Setech, 2007, Fugro, 2012). Joint Industry programmes of static and slow (non-dynamic) cyclic lateral pile tests have been conducted along with axial testing on the same piles (Dührkop et al., 2015, Ciavaglia et al., 2017a, 2017b). Laboratory index, CRS 
oedometer, UCS, static and cyclic direct simple shear and triaxial and resonant column tests have been performed in conjunction with cross-hole and down-hole seismic logging and pressuremeter tests. The Imperial College (IC) research tests were conducted on flat ground approximately $60 \mathrm{~m}$ away from the previous study areas; see Fig. 1. New CPT tests with pore pressure measurement (CPTu) were undertaken in this area. Summaries of the profile, CPT traces and remarkably high piezocone $\mathrm{u}_{2}$ pore pressures encountered are given in Fig. 2.

Laboratory testing

Classification tests, summarised in Table 1, show mainly low density chalk with intact dry densities (IDD) from 1.38 to $1.54 \mathrm{Mg} / \mathrm{m}^{3}$ (Bowden et al., 2002) with a medium density layer between 2.9 and 3.3m, where IDD reaches $1.64 \mathrm{Mg} / \mathrm{m}^{3}$. While ground water is reported around $11.6 \mathrm{~m}$ below the quarry base, the degree of saturation is high above the water table (Table 1). Bishop apparatus ring shear tests by the Authors against mild steel interfaces representing 'field pile' roughnesses, gave residual interface friction angles, $\delta_{\mathrm{r}}$ between 30 and $31^{\circ}$; similar values were reported by Le et al. (2014) and Ziogos et al. (2016). Intact chalk is markedly brittle, failing at less than $0.1 \%$ local axial strain in triaxial tests (Jardine et al., 1984). Lord et al. (2002) indicate intact c' values from $100 \mathrm{kPa}$ to $>2 \mathrm{MPa}$, with $36^{\circ}<\varphi^{\prime}<42^{\circ}$. Remoulded chalk generally mobilises $\varphi^{\prime}$ between 29 and $34^{\circ}$ with $0<c^{\prime}<10 k P a$ (Clayton, 1978, Razoaki, 2000, Bundy, 2013). Peak failure stresses from triaxial tests on intact and remoulded samples from the site are shown on Fig. 3. Consolidated drained triaxial tests on intact samples show a markedly brittle response with best fit peak $c^{\prime}=390 \mathrm{kPa}$ and $\varphi^{\prime}=41^{\circ}$ developing at small strains $(<0.2 \%)$, while undrained triaxial compression tests on remoulded samples showed ductile behaviour with tentative peak $\varphi^{\prime}$ angles of between $\approx 36$ and $38^{\circ}$ (for low and medium densities respectively), when zero $c^{\prime}$ is assumed. Further details on the triaxial test results are included in Appendix A.

\section{Cone penetration tests}

Multiple CPT tests in the test area indicated $\mathrm{q}_{\mathrm{c}}$ varying moderately spatially, showing the trend summarised in Fig. 4. Most $\mathrm{q}_{\mathrm{c}}$ values fell between 10 and $20 \mathrm{MPa}$, with a $100<\mathrm{f}_{\mathrm{s}}<500 \mathrm{kPa}$ range. Thin, discrete and discontinuous flint bands gave sharp local peaks in cone resistance up to 60MPa that are not thought to have influenced the pile tests unduly. The maximum pore pressures recorded exceeded 4MPa over the depth of interest. CPTu dissipation tests at 3.5 and $3.6 \mathrm{~m}$ depth indicated $50 \%$ equalisation times, $\mathrm{t}_{50}$ of between 4 and 
13 seconds, confirming findings by Diambra et al. (2014) and indicating radial coefficients of consolidation, $\mathrm{c}_{\mathrm{h}}$ of 5 to $15 \times 10^{-4} \mathrm{~m}^{2} /$ year when suitable (high) rigidity indices are assumed for the intact chalk. The degree to which drainage takes place around the tips of piezocones or piles during steady penetration may be assessed from the non-dimensional velocity defined by Finnie and Randolph (1994) as:

$$
\mathrm{V}=\frac{\mathrm{vD}}{\mathrm{c}_{\mathrm{h}}} \quad \text { Eq. } 1
$$

Where $D$ is the penetrometer diameter and $v$ is its velocity. For CPTu pore pressure dissipation tests, the appropriate "operational" coefficient of consolidation, $c_{h \text {, piezo }}$ for use in Eq. 1 lies within the range $c_{h, N C}<c_{h, \text { piezo }}$ $<c_{h, O C}$ where $c_{h, N C}$ and $c_{h, O C}$ are the values for normally consolidated and overconsolidated conditions, respectively (Leroueil et al., 1995, Fahey and Lee Goh, 1995). Centrifuge tests on normally consolidated clays and silts show a transition from partially drained to fully undrained conditions at non-dimensional velocities between 10 and 100 when a $\mathrm{c}_{\mathrm{h}, \mathrm{NC}}$ value is used in Eq.1; Finnie and Randolph (1994), Randolph (2004), Cassidy (2012), Suzuki (2014). Fahey and Lee Goh (1995) suggest that $c_{h \text {, piezo }}$ is around $5 c_{h, N c}$, making the transition $V$ range 2 to 20 when $\mathrm{c}_{\mathrm{h} \text {, piezo }}$ is employed. Applying these estimates to the $43.8 \mathrm{~mm}$ diameter piezocones advancing at $20 \mathrm{~mm} / \mathrm{s}$, gives $0.54<\mathrm{V}<1.76$, indicating some partial drainage can be expected during penetration. The same conclusion results from assuming the CPTu end bearing mechanism extends approximately two diameters below the cone tip and noting that the dissipation tests indicate $40 \pm 15 \%$ pore pressure dissipation over the 3.6 seconds required to pass through the failure zone.

\section{PILE AND DRIVING DETAILS}

Seven $139 \mathrm{~mm}$ diameter, tubular steel (API 5CT Grade L80/N80) piles (DP) with an average wall thickness, $t_{\text {wall }}$ of $8.5 \mathrm{~mm}$ were driven on $19^{\text {th }}$ October 2015 to penetrations of $\approx 5.5 \mathrm{~m}$ using a 4 T Junttan SHK100-4 hydraulic impact hammer, leaving $1 \mathrm{~m}$ of pile above ground to facilitate testing. Fig. 5 shows the blow count profiles recorded over the 4 to 16 minutes required to drive each pile. Principally coring behaviour was observed; the internal soil columns of DP1, DP4 and DP5 stood between 0.26 and $0.82 \mathrm{~m}$ above ground at the end of driving, but remained 0.18 to $0.43 \mathrm{~m}$ below ground with the other four piles. Strain gauges and accelerometers were attached near the heads of DP1, DP4 and DP7 and dynamic driving data recorded with Pile Driving Analyser (PDA) software. 
Lim and Lehane (2014) highlight the intrinsic limitations and uncertainties of inferring static capacity from dynamic driving monitoring including the effects of delays following driving. The Authors avoided the latter by pre-installing all sensors and monitoring uninterrupted continuous driving. As detailed in Appendix B, back analysis of the measured force and velocity signals was conducted using IMPACT (Randolph, 2008) which includes explicit modelling of both the internal and external shaft resistance. The best matches between measured and calculated force and force times pile impedance, $Z$ were obtained by applying $85-90 \%$ of the resistance on the outer shaft, which is consistent with trends reported from instrumented piles (Chow, 1997). The average End of Driving (EoD) total shaft load was 39.3kN. Fig. 6 presents the final profiles of total (internal and external) shaft resistance against depth. The average end bearing at EoD, including the contribution from the internal shaft resistance, was $15.8 \mathrm{MPa}$. The average EoD external shaft shear stresses of 15 to $17 \mathrm{kPa}$, comparable to the 11 to $23 \mathrm{kPa}$ range reported at EoD for $762 \mathrm{~mm}$ diameter $4 \mathrm{~m}$ long open steel piles driven at the same site by Ciavaglia et al. (2017b), fall 15 to $25 \%$ below the CIRIA 20kPa recommendation for static shaft capacity in low-medium density chalk (Lord et al., 2002). However, markedly higher local resistances are interpreted over the lowest 1 to $1.5 \mathrm{~m}$ of the shaft from the signal matching, which tend towards the CPTu $\mathrm{f}_{\mathrm{s}}$ value of $\approx 200 \mathrm{kPa}$ and decayed sharply with additional distance, $\mathrm{h}$ above the tip. The variations, which do not correlate with chalk property changes with depth, confirm a strong influence of " $h / R^{\prime \prime}$ on installation shaft resistance.

Substituting $c_{h \text {, piezo }}$ and the field penetration velocities into Eq. 1 indicates partially drained behaviour for the piles with $0.25<V<3.07$, if the piles are considered open-ended with effective radii $R^{*}$. Scaling up from the piezocone dissipation $t_{50}$ times by the ratio of $\left(R^{*} / R_{C P T u}\right)^{2}$ and applying the static driving velocity ranges of the piles, allows the $\mathrm{h}$ values at which tip generated pore pressures dissipated by $50 \%$ to be estimated as 210 to $690 \mathrm{~mm}$. Higher degrees of equalisation can be expected at greater $\mathrm{h}$ values, where longer times elapse after the local excess pore pressures were generated at the tip. The chalk putty annulus formed around the shaft is likely to experience degrees of consolidation and void ratio reduction during driving that depend on $h / R$. Given the kinematic restraint provided by the surrounding stiff chalk mass, the putty's volume straining will also reduce the effective stresses acting on the pile shaft. Lower degrees of shaft 'consolidation during driving' are likely to apply to larger piles and/or those that penetrate more rapidly, as in the free falling 'pile runs' that can occur when installing large monopiles in chalk (Norrie 2015). 


\section{THE EFFECTS OF PILE INSTALLATION ON THE SURROUNDING CHALK MASS}

Conditions surrounding the shaft of the aged piles were examined by partial exhumation of two piles after testing. Trial pits were excavated to maximum $1.1 \mathrm{~m}$ depth adjacent to DP1 and DP7, 274 days after driving. A schematic description of the chalk fabric developed around the piles is shown on Fig. 7, while Fig. 8 shows the variations in water content with depth, $z$ and normalised radial distance from the pile centre, $r / R$. The conditions observed around the piles can be summarised as:

- Zone A: 0-14mm from pile wall, remoulded chalk (assumed to have puttified during driving) with no distinct features. A 1-2mm thick mottled brown oxidised surface adjacent to the surface of the pile giving evidence of redox reactions involving the pile steel. Water contents $\left(w_{c}\right)$ range from 19.5 to $24.9 \%$ (average $=22.8 \%$ ), falling below the undisturbed far-field average of $29.9 \%$;

- Zone B: 14-50mm from pile wall - intact chalk with gritty fragments, crumbles between fingers into dice sized bocks. Evidence of recent fracturing with no iron staining; $\mathrm{w}_{\mathrm{c}}$ ranges from 25 to $28 \%$ (average $=$ 26.5\%). This zone is discontinuous and was not encountered at all depths;

- Zone C: Intact chalk which breaks into bigger blocks. Fractures iron stained (old) and open to $<3 \mathrm{~mm} ; \mathrm{w}_{\mathrm{c}}$ ranges from range 26.4 and $31.3 \%$, with the average of $28.4 \%$ slightly lower than the far-field mean.

The remoulded zone's thickness, $t_{\text {zone }}$ varied from 0.59 to 1.64 times the pile wall thickness as shown on Fig. 7 and Fig. 8. Muir Wood et al. (2015) exhumed a previously tested $762 \mathrm{~mm}$ diameter pile and report a remoulded annulus of 0.78 to 1.57 times twall. The same Authors found remoulded zones formed around steel driven plates whose width amounted to approximately $40 \%$ of the varying plate's thicknesses. Evidence of the conditions under which the remoulded zone formed was presented in the present study by natural fractures and marl seams which terminated and curved sharply downwards at the zone's outer edge. There was no sign of any shear surface close to the pile, or within the chalk mass, having formed during static loading, that could be separated confidently from the remoulded zone that formed during driving. As argued earlier, the remoulded zone probably underwent at least partial contemporaneous consolidation that contributed to the driving ' $h / R^{\prime}$ effects identified in Fig. 6 through relaxation of the shaft radial effective stresses. Jardine et al. $(2006,2013)$ argue that similar radial effective stress reductions take place around piles driven in sand and that subsequent 
creep processes allow the arching mechanisms generated around the shafts to relax and so contribute to shaft capacity growth with time.

\section{STATIC AND CYCLIC TESTING PROGRAMME}

The dynamic driving analysis provided estimates for the piles' average EoD 'initial' compressive shaft resistance. The post-driving ageing trends were tracked by 'slow' static tension tests conducted at four ages on three virgin piles, and one pre-tested pile, as summarised in Table 2.

The effects of slow (non-dynamic) cyclic loading on aged piles were investigated through the separate programme summarised in Table 3, testing four virgin piles 247 to 255 days after driving. The first cyclic experiment, DP7, imposed 1000 medium level cycles before a 'quick' static test to failure in tension. Piles DP1, DP4 and DP5 were initially all subjected to $\geq 1000$ relatively low level cycles, which led to little or no stiffness loss and modest displacements. Two of the three piles (DP1 and DP5) were then subjected, without delay, to cycling at higher normalised load levels. 'Quick' tension load tests to failure followed in both cases. Pile DP4 was initially subjected to 1000 relatively low level cycles, followed immediately by a "quick" static test to failure. A second higher level cyclic test was performed six days later.

\section{EXPERIMENTAL PROCEDURES}

The static and cyclic tests were all conducted with the load and control equipment shown in Fig. 9, which was designed and built at Imperial College. The static and cyclic tests were conducted in tension to allow the shaft friction to be determined without any base instrumentation, which was not feasible for the tests in this study. Pile head displacements were monitored by three Linear Variable Differential Transformers (LVDTs) spaced evenly circumferentially around the pile and attached to an independent reference frame supported on stands set $1 \mathrm{~m}$ from the pile centre. The 'slow' static test loads were applied in increments of $10 \%$ of the expected failure capacity, each imposed over 1 minute, followed by monitored pause periods that extended as failure approached. Pile failure was defined as either i) displacement reaching $10 \%$ of the diameter, D or ii) the semilogarithmic pile creep-displacement rate $\mathrm{k}_{\mathrm{s}}$ measured under constant load exceeding $0.2 \mathrm{~mm} / \log$ cycle of time after ten or more minutes. The latter rate was scaled from the Ea-Pfähle (2014) criterion of $\mathrm{k}_{\mathrm{s}}>2 \mathrm{~mm}$ per log cycle of time to reflect the test pile dimensions. The load steps and creep pause durations depended on the creep monitoring data. Ten to twelve load steps were required to reach failure and tests took two to three hours 
to complete. Additional 'quick' load tests were performed following selected cyclic tests that led to failure in less than thirty minutes.

The cyclic loading system could impose two to four cycles per minute $(0.03$ to $0.06 \mathrm{~Hz})$ for thousands of cycles and control the peak loads to $+/-2 \%$. Sine wave loading was not achievable with the systems available. The adopted square wave, plus twin exponential section, cyclic load characteristic is shown in Fig. 10, where the average $\left(Q_{\text {mean }}\right)$ and cyclic $\left(Q_{\text {cyc }}\right)$ loading components are also defined. Table 5 lists the cyclic loading parameters associated with each test, which are referred to the current net static tension capacity, $Q_{t}$, of each pile, proven by the independent static test results. Cyclic failure manifests as rapidly accumulating permanent displacement and decreasing global stiffness and failure was defined as either i) permanent displacement reaching 0.1D (Yang et al., 2016) or ii) a sudden increase in the rate of displacement accumulation, indicative of decreasing stability and approaching cyclic failure. 
Tension tests were conducted to failure 10, 106 and 246 days after driving on three virgin piles; DP2, DP3 and DP6, which gave the peak capacities, corrected for pile and chalk plug self-weight, summarised in Table 4. Reverse end bearing is assumed negligible as the fractured chalk drains very rapidly and final static holding periods were typically greater than 30 minutes, far exceeding the dissipation time anticipated for any reverse end bearing mechanism. The piles' overall net axial load displacement responses are shown in Fig. 11, along with the average compressive EoD shaft capacity of DP1, DP4 and DP7 from the dynamic analysis described in Appendix B. Fig. 12 plots the peak static tension loads, corrected for pile and soil self-weight divided by the EoD compressive shaft capacity, against time. The closed symbols indicate the Intact Ageing Characteristic (IAC) of the virgin piles (Jardine et al. (2006)), while the open symbol shows the retest on pile DP2, completed 227 days after installation and 217 days after its 10 day static tension failure. If compression and tension shaft capacities are equal, then Fig. 12 indicates a set up factor of 5.2 after 246 days for the fresh piles, with mean shaft resistance growing from $\approx 16$ to $86 \mathrm{kPa}$. Most of the beneficial ageing occurs over the first 100 days; the rates of change slow with time and may tend to a final equilibrium.

Empirical relationships have been suggested to represent such trends in clays and sands (Skov and Denver, 1988, Mesri et al., 1990, Bogard and Matlock, 1990, Tan et al., 2004). The hyperbolic relationship suggested by Tan et al. (2004) appears appropriate, where the shaft capacity $Q$ available at time $t$ is:

$$
\mathrm{Q}(\mathrm{t})=\mathrm{Q}_{\mathrm{u}}\left[\mathrm{m}+(1-\mathrm{m})\left(\frac{\frac{\mathrm{t}}{\mathrm{T}_{50}}}{1+\frac{\mathrm{t}}{\mathrm{T}_{50}}}\right)\right] \quad \text { Eq. } 2
$$

where $Q_{u}$ is the projected ultimate equilibrium capacity, $T_{50}$ is the time required to achieve $50 \%$ of $Q_{u}$ and $m$ is an empirical coefficient (around 0.2) applied to improve the fit at the early ( $t<1$ day) age. The curve plotted on Fig. 12 corresponds to $Q_{u}=225 \mathrm{kN}, \mathrm{m}=0.2$ and $T_{50}=27$ days. The single re-test confirmed that beneficial ageing was disrupted by previous static failure; the pre-failed DP2 showed 32\% less gain in capacity over its 10 to 227 day age range than the equivalent virgin pile DP6.

The three static tests shown on Fig. 11 appear to follow similar initial global stiffness trends before curving towards their age-dependent failure loads. Global secant stiffness can be quantified as load change $\Delta \mathrm{Q}$ from the initial 'nip-load,' applied to ensure loading system stability, divided by total displacement from the same origin. 
The three tests' stiffness trends are plotted over the course of each stage in Fig. 13, along with the retest on pile DP2. The stiffness-load trends show highly non-linear trends from their first increment onwards, as is common in soils (Jardine et al., 2005b). All three virgin curves share broadly similar initial stiffness of 100 to $200 \mathrm{kN} / \mathrm{mm}$ at a $20 \mathrm{kN}$ load level, with the 106 and 246 day aged piles also showing similar stiffnesses over a range of loading levels. The re-tested pile shows significantly stiffer behaviour initially, which subsequently degraded at lower load levels than the virgin piles.

\section{CYCLIC TEST RESULTS \& INTERPRETATION}

The definitions of the accumulated cyclic displacement parameters applied to the cyclic tests were given by Rimoy et al. (2013). The growth of permanent displacement, $s_{\text {acc }}$ normalised by $D$, with the number of cycles, $\mathrm{N}$, is plotted for the six cyclic experiments in Fig. 14 and 15. The four non-failing tests (Fig. 14 a to d) follow approximately constant logarithmic gradients once $\mathrm{N}>20$. The implied power law trends have the form:

$$
\frac{s_{\text {acc }}}{\mathrm{D}}=\mathrm{AN}^{\mathrm{B}} \quad \mathrm{Eq} \cdot 3
$$

where A and B are non-dimensional fitting parameters. The re-test presented in Fig. 14 e) shows a broadly comparable but more staggered trend. The two unstable tests, presented in Fig. 15, failed at low $\mathrm{N}$ values and, as discussed later, demonstrated marked losses of shaft capacity.

The six tests' normalised $\mathrm{Q}_{\text {mean }}$ and $\mathrm{Q}_{\mathrm{cyc}}$ loading components are plotted on an axial cyclic interaction diagram (Karlsrud et al., 1986, Poulos, 1988, Jardine and Standing, 2000, 2012) on Fig. 16. In this Figure, the numbers of cycles imposed are also noted, falling below 1000 for the two tests that failed cyclically. The tension capacities employed to normalise the loads for each test age were obtained from Eq 2, as given in Table 5. The top-left to right-bottom diagonal in this diagram represents the static failure conditions, where the Utilisation of tension shaft capacity Ratio, $U R=Q_{\max } / Q_{t}$ is equal to 1 . The line representing the minimum $U R=2 / 3$ recommended by API and ISO guidance for extreme offshore environmental loading cases is also shown, along with an UR $=0.5$ line. Tentative contours of $\mathrm{N}=10,100$ and 1000 are plotted to indicate the conditions under which cyclic failure could be expected under given normalised cyclic load combinations. 
Axial cyclic stiffness

The experiments also revealed how global cyclic secant stiffness evolved during each cyclic test. Stiffness was assessed by the loading or unloading terms, kı and ku defined by Rimoy et al. (2013). Fig. 17 a) shows the loading stiffness trends, normalised by the first cycle value, for the four unfailed tests. Two of these showed $k_{l}$ and $k_{u}$ increasing consistently under cycling and reaching gains of up $30 \%$ at $N=1000$. The two other "unfailed" tests showed stiffness reducing up to 200 cycles, before increasing to reach almost 1.05 times the initial value at $N=$ 1000. Fig. 17 b) presents the two failed tests' tends: DP1-CY2 showed stiffness degrading from the first cycle falling by over $60 \%$ prior to final failure. Degradation was less marked in DP5-CY2 initially, but reached a similar level before final cyclic failure. As expected, stiffness degradation was generally slightly more marked on reloading than on un-loading so leading to displacement accumulation during cycling. Re-test DP4-CY2, completed 6 days after test DP4-CY1 and a subsequent tension test to failure, showed gentler degradation trends and more stable normalised behaviour (Fig. 17a) than the initial cyclic test at lower load levels. It appears that stiffness recovers and normalised resistance grows with time following cyclic or static failure.

Impact on tension capacity

The post-cyclic tension tests are summarised in Table 5. Those following the "unfailed" experiments DP4-CY1 and DP7-CY1 indicated relatively modest changes in capacity ( $5 \%$ increase and $14 \%$ reduction respectively) when compared to the static trends predicted by Eq 2. However, cyclic failure led to more marked losses of $24 \%$ and 43\% following DP5-CY2 and DP1-CY2, respectively.

\section{Cyclic stability criteria}

Cyclic axial loading tests on piles driven in clays and sands show trends that have been classified as Stable, Metastable or Unstable: (Karlsrud et al., 1986, Poulos, 1988, Jardine and Standing, 2000, Tsuha et al., 2012, Jardine et al., 2012). Jardine \& Standing (2012) and Rimoy et al. (2013) applied working definitions in their interpretation of open tube piles driven in dense sand at Dunkirk that referred to both possible numbers of cycles $\mathrm{N}$ and rates of permanent cyclic displacement accumulation, with:

- Stable (S): No failure within 1000 cycles. Pile displacements accumulate slowly over hundreds of cycles and tend to stabilise with cycling, remaining below $0.01 \mathrm{D}$ and showing rates of change of less than $1 \mathrm{~mm} / 1000$ 
cycles and negligible loss of cyclic stiffness. Cycling in this range does not affect foundation serviceability or reduce operational shaft capacity;

- Unstable (US): pile displacements accumulate rapidly leading to cyclic failure at $\mathrm{N}<100$ with either accumulated displacements greater than $0.1 \mathrm{D}$ or a rate of accumulation of displacement greater than $1 \mathrm{~mm} / 10$ cycles. The foundations may become unserviceable and potentially suffer marked reductions in operational shaft capacity;

- Metastable (MS): transitional behaviour where cycling may lead to failure with $100<\mathrm{N}<1000$ and pile displacements developing at moderate rates over tens to hundreds of cycles without stabilisation. Serviceability and operational shaft capacity losses depend on numbers of cycles applied. Displacements of $0.01 \mathrm{D}$ to $0.1 \mathrm{D}$ develop at rates between $1 \mathrm{~mm} / 1000$ cycles and $1 \mathrm{~mm} / 10$ cycles.

Table 5 lists the outcomes of the cyclic loading tests. Applying the above categories, two of the tests (DP1-CY2, DP5-CY2) are unstable. The remaining four (DP1-CY1, DP4-CY1, DP5-CY1 DP7-CY1) classify as stable in terms of reaching 1000 cycles without failure or significant loss in operational tension capacity, but meta-stable with regards to accumulated displacements. The transition between unstable and metastable or stable behaviour appears to be abrupt. Fully stable behaviour was not observed, except in test DP4-CY2, which had been prefailed, within the limited region of the interactive diagram that could be explored. Bearing in mind the tests involved purely one way loading at $U R \geq 0.48$, the stable region of behaviour appears to be more limited than was found, for example, by Jardine and Standing (2012) for Dunkirk sand. Jardine et al. (2012) emphasise that higher cyclic $Q_{c y c} / Q_{t}$ amplitudes are likely to have a greater impact in two-way loading tests conducted with maximum loads set to achieve the same UR values; UR is not an adequate parameter on its own to characterise cyclic loading.

\section{Permanent accumulated displacements}

Under the limited range investigated, the virgin piles' permanent displacement accumulation trends correlate with UR. The unstable tests showed different accumulated displacement trends; test DP1-CY2 subjected to cyclic and average loads equivalent to a 'static' UR of 0.79 , accumulated displacements of 2.3 to $3.4 \mathrm{~mm}$ from its start and failed in 5 cycles. Displacement accumulation was more gradual in unstable test DP5-CY2 (under a 'static' 
UR of 0.70 ) remaining below $0.1 \mathrm{~mm} /$ cycle for the first 9 cycles, before more rapid accumulation led to failure in 32 cycles.

Three of the four Stable/Meta-stable tests (DP1-CY1, DP5-CY1 and DP7-CY1) exhibited consistent behaviour when subjected to cycling at loads equivalent to $0.48<U R<0.58$. While their displacement accumulation rates may have stabilised eventually, they followed the power law function given as Eq. 3 over $20<\mathrm{N}<1000$, with coefficients $A$ and $B$ of $0.0015 \pm 0.0004$ and $0.32 \pm 0.03$ respectively; see Fig. 18 . The remaining MS/S test (DP4CY1), whose loads implied an equivalent static UR of 0.70 , followed a steeper power law trend $(A=0.0008$, $B=0.49$ ) that may have accelerated and led to eventual failure if cycling had continued. The global trends must reflect locally progressive top-down degradation (Jardine et al., 2012) that can only be checked through the use of local instrumentation. The coefficient A, can therefore be expected to vary with chalk profile, pile shaft length and cross section.

Finally, Fig. 19 shows the permanent displacements plotted on cyclic stability interaction diagrams, considering cases with $\mathrm{N}=3,10,20,100,300$ and 600 . Contours are indicated for $\mathrm{s}_{\mathrm{acc}} / \mathrm{D}$ ratios of $0.2 \%, 0.5 \%$ and $2.0 \%$ for these one way cyclic tests. Further tests are required to examine potential pile scale effects and the influence of high-level two-way loading.

\section{CONCLUSIONS}

Improved guidance is required urgently to help design a wide range of wind-energy and other structures that are founded on piles driven in chalk. This paper reports programmes of static and cyclic loading tests on open steel tubes driven in low-medium density chalk that showed:

1. Notably low shaft resistances during driving along their main shaft lengths;

2. A strong dependence of local shaft resistance on relative distance above the pile tip (h/R);

3. Marginally lower average shaft driving resistances than the CIRIA static design guidance values;

4. Static tension capacities increasing markedly after driving. Gains exceeding $500 \%$ were interpreted after eight months, leading to average shaft stresses that exceeded the low-medium density guidance value by a factor of 4.3 ; 
5. A hyperbolic shaft capacity trend with time that was $83 \%$ complete 100 days after installation. A single re-test conducted 8 months after one pile's first static failure showed a positive ageing trend, although its capacity fell well below that of the undisturbed piles;

6. Driving remoulded the chalk, creating a puttified zone and probably very high excess pore pressures near to the pile tip. Rapid excess pore water pressure dissipation during and after driving led to markedly lower water contents close to the shaft;

7. Short-term reconsolidation that was too rapid to explain, on its own, the observed long-term increases in shaft capacity. Mechanisms involving early consolidation of chalk putty (contemporaneously with pile driving) followed by creep of radial effective stresses may provide explanations for the observed ageing trends, taken in combination with potential re-cementing and the redox chemical reactions that were noted to have occurred close to the pile shafts;

8. A range of responses to axial cyclic testing around 250 days after driving. One-way (non-dynamic) cycling that involved equivalent 'static' utilisation ratios $>0.70$ led to clearly unstable behaviour with rapid accumulation of displacement, stiffness loss, failure in far less than 100 cycles and marked degradation in operational shaft capacity. One-way tests conducted with $0.48<U R<0.70$ led to broadly stable capacities and cyclic stiffness remaining constant or growing as cycling continued. However, the piles' accumulated displacement trends did not stabilise within 1000 cycles, suggesting only meta-stability. Greater degradation can be expected at the same UR values under high-level two-way loading;

9. The permanent displacement accumulation trends followed under the stable/metastable tests developed proportionally with $N$, raised to an exponent of $\approx 1 / 3$ that appeared to be insensitive to the loading parameters within the limited range (one-way $0.48<U R<0.70$ ) considered. Higher exponents applied in the unstable range. Further investigation is required to explore the potential effects of pile scale and chalk density, as well as the cyclic response under a wider range of cyclic loading conditions;

10. The experiments provide the first systematic study of which the Authors are aware into the effects of undisturbed ageing and cyclic loading of previously unfailed piles driven in chalk. Overall, guidance based on driving monitoring and early age tests is shown to be potentially highly conservative, while cyclic tests on aged piles showed responses that varied between stable and unstable, depending on the loading conditions. Potential predictive tools, which range from purely empirical global approaches through to 
fully numerical analysis with advanced constitutive models, may now be tested against the reported field measurements.

\section{ACKNOWLEDGEMENTS}

This study is part of a joint industry project led by Pedro Barbosa that is funded by Innovate UK (formerly the Technology Strategy Board), Iberdrola/Scottish Power Renewables and supported by the Geotechnical Consulting Group, London. The Authors acknowledge the additional financial help and support received from Atkins for this work. The Authors also acknowledge colleagues from Imperial College: Dr. James Lawrence who guided the pile exhumation inspections and Emil Ushev and Tingfa Liu who helped conduct the pile tests. The Authors are also grateful to Professor Mark Randolph for the use of IMPACT, Dr. Francesca Ciavaglia and Dr. John Carey of Wind Support Ltd for providing supporting information on the site, and to Fugro Geoconsulting Ltd who carried out the laboratory testing.

\section{APPENDIX A - TRIAXIAL TEST RESULTS}

Further results from triaxial tests conducted in the Fugro commercial laboratory on samples from the site are shown on Figs 20 and 21. Fig. 20 shows the effective stress paths and stress-strain behaviour of consolidated undrained triaxial compression tests on remoulded samples, as consolidated both isotropically and under $\mathrm{K}_{0}$ conditions. Fig. 21 presents the stress-strain behaviour observed during drained triaxial compression tests on intact samples. The axial strains shown in Fig. 20 and 21 are interpreted from the Fugro results, and show average local strain measurements (made with Hall effect gauges) plotted as solid lines up to the points where the sensors become less reliable than the external strain measurements, which were adopted to construct the later stage stress-strain curves and are plotted as dashed lines. A key point to note is the marked brittleness shown by the drained test on intact samples after they reached peak deviator stress at relatively small strains $(<0.2 \%)$. 
Back analysis of the force and velocity signals measured near the pile head was undertaken to obtain static capacity employing IMPACT (Randolph, 2008), a signal matching program which includes models for soil resistance at the base and shaft based on elasto-dynamic theory (Randolph and Simons, 1986, Deeks and Randolph, 1995). The paragraphs below provide a brief description of the models used in the analyses.

The shaft model is based on the analytical solution for the dynamic load transfer stiffness of an elastic soil acting on the shaft of a rigid, long pile under vertical vibration (Novak et al., 1978). Conditions at the pile soil interface are simulated by a viscous dashpot in parallel with a plastic slider and the far field is modelled with an elastic spring and a dashpot which represents radiation damping. The shear resistance in the far field is given by:

$$
\tau=G\left[\frac{W}{\mathrm{D}}+\frac{v_{p}}{\mathrm{~V}_{\mathrm{s}}}\right] \quad \text { Eq. } 4
$$

where $w$ is displacement, $v_{p}$ is particle velocity in the pile, $\mathrm{D}$ is the pile diameter, $\mathrm{G}$ is the shear modulus and $\mathrm{V}_{\mathrm{S}}$ is the shear wave velocity $\left(V_{s}=\sqrt{G / \rho_{s}}\right)$, where $\rho_{s}$ is the soil mass density). A limiting shaft resistance is used to model the interface, expressed as a function of the relative velocity between the pile and the soil:

$$
\tau_{\text {inter }}=\tau_{\mathrm{s}}\left(1+\alpha\left(\Delta \mathrm{v} / \mathrm{v}_{0}\right)^{\beta}\right) \quad \text { Eq. } 5
$$

where $\tau_{\mathrm{s}}$ is the static resistance of the pile, $\mathrm{v}_{0}$ is equal to $1 \mathrm{~m} / \mathrm{s}, \Delta \mathrm{v}$ is the relative velocity between pile and soil and $\alpha$ and $\beta$ are empirical viscosity parameters. IMPACT includes implicit modelling of the internal as well as external shaft resistance, with the internal soil modelled in a similar manner to Eq. 4 and 5. The Deeks and Randolph (1995) base model is similar to the shaft model described with the exception of lumped masses connected to the pile and a supplementary radiation dashpot. The resistance at the pile base is represented by:

$$
\mathrm{Q}_{\mathrm{b}}=\frac{4 \mathrm{GR}}{1-\mu} \mathrm{w}+\frac{3.2 \mathrm{R}^{2} \sqrt{\mathrm{G} \rho_{\mathrm{s}}}}{1-\mu} \mathrm{v}_{\mathrm{p}} \quad \text { Eq. } 6
$$

The lumped mass is represented by:

$$
\mathrm{m}_{0}=1.28 \mathrm{R}^{3} \rho_{\mathrm{s}} \quad \text { Eq. } 7
$$

Where $\mu$ is Poisson's ratio and $\mathrm{R}$ is the pile radius. The plastic slider is limited to the static end bearing capacity, $q_{b, l i m}$ entered by the user. No allowance is made for viscous effects at the pile base. 
The measured pile force and pile velocity times impedance, $Z$ measured at the pile head were used as input to the program and signal matching was carried out by comparison of the calculated and measured upward travelling waves. The remaining inputs are shear modulus, soil density, limiting internal and external shaft resistance and base resistance. The Authors' initial trial parameter sets were gauged from the site investigations described in the main text. Consistent with the approach adopted by Salgado et al. (2015) the shear modulus used in the analyses was the secant modulus, $G_{1}$ at values degraded from the small strain $\left(G_{\max }\right)$ equivalent to $\approx 20 \% \mathrm{G}_{\text {max }}$. Fig. 22 shows the partial measured and calculated velocity and force time histories from a typical result. The average external compressive shaft load at EoD was $39.3 \mathrm{kN}$.

\section{NOTATION}

\section{Roman Alphabet}

\begin{tabular}{|c|c|}
\hline A, B & Power law parameters \\
\hline$c^{\prime}$ & Cohesion intercept \\
\hline $\mathrm{c}_{\mathrm{h}}$ & Coefficient of radial consolidation \\
\hline $\mathrm{c}_{\mathrm{h}, \mathrm{NC}}$ & Coefficient of radial consolidation under normally consolidated conditions \\
\hline $\mathrm{c}_{\mathrm{h}, \mathrm{OC}}$ & Coefficient of radial consolidation under overconsolidated conditions \\
\hline $\mathrm{c}_{\mathrm{h}, \text { piezo }}$ & Operational coefficient of radial consolidation during CPTu dissipation tests \\
\hline D & Diameter of pile or penetrometer \\
\hline $\mathrm{f}_{\mathrm{s}}$ & CPT sleeve friction \\
\hline G & Shear modulus \\
\hline $\mathrm{G}_{\mathrm{s}}$ & Particle density \\
\hline $\mathrm{G}_{\max }$ & Maximum shear modulus \\
\hline $\mathrm{G}_{1}$ & Secant shear modulus \\
\hline $\mathrm{h}$ & Distance from the pile tip \\
\hline $\mathrm{I}_{\mathrm{p}}$ & Plasticity index \\
\hline $\mathrm{k}_{\mathrm{l}}$ & Cyclic loading stiffness \\
\hline $\mathrm{k}_{\mathrm{s}}$ & Displacement creep rate \\
\hline $\mathrm{k}_{\mathrm{u}}$ & Cyclic unloading stiffness \\
\hline $\mathrm{m}$ & Empirical factor describing hyperbolic ageing trend \\
\hline $\mathrm{m}_{0}$ & Lumped mass \\
\hline $\mathrm{N}$ & Number of cycles \\
\hline $\mathrm{q}_{\mathrm{b}, \mathrm{lim}}$ & Limit base resistance \\
\hline $\mathrm{q}_{\mathrm{c}}$ & CPT cone resistance \\
\hline $\mathrm{qu}_{\mathrm{u}}$ & Unconfined compressive strength \\
\hline $\mathrm{Q}_{\mathrm{b}}$ & Pile base capacity \\
\hline$Q_{\text {cyc }}$ & Axial cyclic load amplitude \\
\hline
\end{tabular}




$\begin{array}{ll}Q_{\text {mean }} & \text { Mean axial cyclic load } \\ Q_{t} & \text { Current pile capacity in tension } \\ Q_{t(E O D)} & \text { Static compressive tension capacity at EoD from dynamic tests } \\ Q_{u} & \text { Ultimate equalised pile capacity in tension } \\ r & \text { Distance from the pile centre } \\ R & \text { Pile radius } \\ R_{c p t u} & \text { CPTu radius } \\ \mathrm{R}^{*} & \text { Open ended pile effective radius } \\ \mathrm{S}_{\mathrm{acc}} & \text { Accumulated permanent cyclic displacement } \\ \mathrm{S}_{\mathrm{r}} & \text { Degree of saturation } \\ \mathrm{t} & \text { Time } \\ \mathrm{t}_{\mathrm{pile}} & \text { Pile wall thickness } \\ \mathrm{t}_{\mathrm{zone}} & \text { Thickness of the zone surrounding the pile shaft } \\ \mathrm{t}_{50} & \text { Time for } 50 \% \text { dissipation of excess pore water pressures in a CPT dissipation test } \\ \mathrm{T}_{50} & \text { Time for } 50 \% \text { set up of ultimate capacity } \mathrm{Q}_{\mathrm{u}} \\ \mathrm{u}_{2} & \text { CPTu pore pressure measured at the uz position } \\ \mathrm{v} & \text { Velocity of the pile or penetrometer } \\ \mathrm{v}_{\mathrm{p}} & \text { Particle velocity } \\ \Delta v & \text { Relative velocity between pile and soil } \\ \mathrm{V} & \text { Dimensionless velocity } \\ \mathrm{V}_{\mathrm{s}} & \text { Shear wave velocity } \\ \mathrm{w} & \text { Displacement in the } \mathrm{z} \text { direction } \\ \mathrm{w}_{\mathrm{c}} & \text { Moisture content } \\ \mathrm{w}_{\mathrm{l}} & \text { Liquid limit } \\ \mathrm{w}_{\mathrm{p}} & \text { Plastic limit } \\ \mathrm{z} & \text { Depth below ground level } \\ \mathrm{Z} & \text { Pile impedance } \\ & \end{array}$

\section{Greek alphabet}

$\begin{array}{ll}\alpha, \beta & \text { Empirical viscosity parameters } \\ \delta_{\mathrm{r}} & \text { Residual interface friction angle } \\ \mu & \text { Poisson's ratio } \\ \rho_{\mathrm{s}} & \text { Soil mass density } \\ \tau_{\mathrm{rz}} & \text { Total shaft resistance } \\ \tau_{\mathrm{s}} & \text { Static shaft resistance in back analysis of dynamic tests } \\ \tau_{\lim } & \text { Limit dynamic static shaft resistance } \\ \varphi^{\prime} & \text { Effective angle of shearing resistance }\end{array}$


Andersen, K. H., Puech, A. \& Jardine, R. J. (2013). Cyclic resistant geotechnical design and parameter selection for offshore engineering and other applications. In Proc. TC 209 Workshop - 18th Int. Conf. Soil. Mech. Geotech. Eng.: 'Design for cyclic loading: piles and other foundations' (Puech, A., (ed)). Paris, France, pp. 9-44: Presses des Ponts

Barbosa, P., Geduhn, M., Jardine, R. J., Schroeder, F. C. \& Horn, M. (2015). Offshore pile load tests in chalk. In Proc. 16th Eur. Conf. Soil Mech. \& Geotech. Eng. (Winter, M. G., (ed)). Edinburgh, Scotland, pp. 28852890: ICE Publishing

Bogard, J. D. \& Matlock, H. (1990). Application of model pile tests to axial pile design. In Proc. 22nd Offshore Technology Conference, Houston, Texas, pp. 271-278: Offshore Technology Conference

Bond, A. J. \& Jardine, R. J. (1991). Effects of installing displacement piles in a high OCR clay. Géotechnique, 41, No. 3, 341-363.

Bowden, A. J., Spink, T. W. \& Mortimore, R. N. (2002). The engineering description of chalk: its strength, hardness and density. Q. J. Eng. Geol. Hydrogeol., 35, No. 4, 355-361.

Buckley, R. M. (2014). Axial cyclic loading of piles in sand. MSc Thesis, Imperial College London, London, UK

Bundy, S. P. S. (2013). Geotechnical properties of chalk putties. PhD Thesis, University of Portsmouth, Portsmouth, UK

Burland, J. B. \& French, D. J. (1990). Results of trials in weathered chalk of a novel piling system - the wedge pile. In Proc. Intl. Chalk Symp. (Burland, J. B. et al., (eds)). Brighton, UK pp. 375-383: Thomas Telford

Carrington, T. M., Li, G. \& Rattley, M. J. (2011). A new assessment of ultimate unit friction for driven piles in low to medium density chalk. In Proc. 15th Eur. Conf. Soil Mech. \& Geotech. Eng. (Anagnostopoulos, A. et al., (eds)). Amsterdam, The Netherlands, pp. 825-830: IOS Press

Cassidy, M. J. (2012). Experimental observations of the penetration of spudcan footings in silt. Géotechnique, 62, No. 8, 727-732.

Chow, F. C. (1997). Investigations into Displacement Pile Behaviour for Offshore Foundations. PhD Thesis, Imperial College London, London, UK

Ciavaglia, F., Carey, J. \& Diambra, A. (2017a). Monotonic and cyclic lateral tests on driven piles in Chalk. Proc. of the ICE Geotech. Eng. , 0, No. 0, 1-14.

Ciavaglia, F., Carey, J. \& Diambra, A. (2017b). Time-dependent uplift capacity of driven piles in low to medium density chalk. Géotechnique Letters 7. March, 1-7

Clayton, C. R. I. (1978). Chalk as Fill. PhD Thesis, University of Surrey, Surrey, UK

Clayton, C. R. I., Matthews, M. C. \& Heymann, G. (2002). The Chalk. In Proc. 1st Intl. Workshop on Characterisation and Engineering Properties of Natural Soils (Tan, T. S. et al., (eds)). Singapore, pp. 1403-1434: CRC Press

Deeks, A. J. \& Randolph, M. F. (1995). A simple model for inelastic footing response to transient loading. Int. J. Num. Meth. Geotech. Eng., 19, No. 5, 307-329.

Diambra, A., Ciavaglia, F., Dimelow, C., Carey, J. \& Nash, D. F. T. (2014). Performance of cyclic cone penetration tests in chalk. Géotechnique Letters 4. July-September, 230-237

Doherty, P., Gavin, K. \& Casey, B. (2011). The geotechnical challenges facing the offshore wind sector. In Proc. of Geo-Frontiers 2011: Advances in Geotechnical Engineering (Han, J. et al., (eds)). Dallas, Texas, pp. 162-171: ASCE

Dührkop, J., Augustesen, A. H. \& Barbosa, P. (2015). Cyclic pile load tests combined with laboratory results to design offshore wind turbine foundations in chalk. In Poc. Conf. Frontiers in Offshore Geotechnics III (ISFOG) (Meyer, V., (ed)). Oslo, Norway, pp. 533-538: CRC Press 
Ea-Pfähle 2014. Recommendations on Piling: Piling Committee of the German Geotechnical Society (abbreviated as: EA Pfähle), Germany: John Wiley \& Sons.

Fahey, M. \& Lee Goh, A. (1995). A comparison of pressuremeter and piezocone methods of determining the coefficient of consolidation. In Proc. 4th Intl. Symp. on the Pressuremeter and Its New Avenues (Ballivy, G., (ed)). Quebec, Canada, pp. 153-60: Balkema

Finnie, I. M. S. \& Randolph, M. F. (1994). Punch-through and liquefaction induced failure of shallow foundations on calcareous sediments. In Proc. Int. Conf. Behavior of Offshore Structures (Chryssostomidis, C., (ed)). Boston, Massachusetts, pp. 217-230: Pergamon

Fugro (2012). Laboratory testing report: Pile test site, chalk specific testing. St. Nicholas at Wade, UK, D34001-2.

Gavin, K., Jardine, R. J., Karlsrud, K. \& Lehane, B. M. (2015). The effects of pile ageing on the shaft capacity of offshore piles in sand. In Poc. Conf. Frontiers in Offshore Geotechnics III (ISFOG), Oslo, Norway, pp. 129151: CRC Press

Hancock, J. M. (1975). The petrology of the Chalk. Proceedings of the Geologists' Association, 86, No. 4, 499-535.

Heerema, E. P. (1978). Predicting pile driveability: heather as an illustration of the friction fatigue theory. In Proc. Eur. Offshore Petroleum Conf., London, UK, pp. 413-422: Society of Petroleum Engineers

Hobbs, N. B. \& Atkinson, M. S. (1993). Compression and tension tests on an open-ended tube pile in chalk. Ground Engineering, 26, No. 3, 31-34.

Jardine, R. J., Symes, M. J. \& Burland, J. B. (1984). The measurement of soil stiffness in the triaxial apparatus. Géotechnique, 34, №. 3, 323-340.

Jardine, R. J. \& Standing, J. R. (2000). Pile Load Testing Performed for HSE Cyclic Loading Study at Dunkirk, France Volume 1 \& 2. , ОTO2000 007.

Jardine, R. J., Chow, F. C., Overy, R. \& Standing, J. R. 2005a. ICP design methods for driven piles in sands and clays, London: Thomas Telford.

Jardine, R. J., Standing, J. R. \& Kovacevic, N. (2005b). Lessons learned from full scale observations and the practical application of advanced testing and modeling. In Proc. 3rd Int. Symp. on Deformation Characteristics of Geomaterials (Di Benedetto, H. et al., (eds)). Lyon, France, pp. 201-245: Balkema

Jardine, R. J., Standing, J. R. \& Chow, F. C. (2006). Some observations of the effects of time on the capacity of piles driven in sand. Géotechnique, 56, No. 4, 227-244.

Jardine, R. J., Puech, A. \& Andersen, K. H. (2012). Cyclic loading of offshore piles: potential effects and practical design. In Proc. 7th Int. Conf. on Offshore Site Investigation and Geotechnics (Allan, P. et al., (eds)). London, UK, pp. 59-97: Society for Underwater Technology (SUT)

Jardine, R. J. \& Standing, J. R. (2012). Field axial cyclic loading experiments on piles driven in sand. Soils Found., 52, No. 4, 723-736.

Jardine, R. J., Zhu, B. T., Foray, P. \& Yang, Z. X. (2013). Interpretation of stress measurements made around closed-ended displacement piles in sand. Géotechnique, 63, No. 8, 613-627.

Jardine, R. J. (2017). Geotechnics and Energy: 56th Rankine Lecture. Géotechnique, to appear.

Karlsrud, K., Nadim, F. \& Haugen, T. (1986). Piles in clay under cyclic axial loading - Field tests and computational modelling. In Proc. 3rd. Int. Conf. on Numerical Methods in Offshore Piling (Du Petrole, F., (ed)). Nantes, France, pp. 165-190: Editions Technip

Karlsrud, K., Jensen, T. G., Lied, E. K. W., Nowacki, F. \& Simonsen, A. S. (2014). Significant ageing effects for axially loaded piles in sand and clay verified by new field load tests. In Proc. 46th Offshore Technology Conference, Houston, Texas, pp. 1-19: Offshore Technology Conference

Lahrs, T. \& Kallias, A. (2013). Probebelastungen von Stahlrohren in Kreide für den Offshore-Windpark Baltic 2. In Proc. Pfahl Symposium, Braunschweig, Germany, pp. 451-466: Pfahl Symposium

Le, T. M. H., Eiksund, G. R., Strøm, P. J. \& Saue, M. (2014). Geological and geotechnical characterisation for offshore wind turbine foundations: A case study of the Sheringham Shoal wind farm. Engineering Geology. 2014, 40-53 
Lehane, B. M. \& Jardine, R. J. (1992a). The Behavior of a Displacement Pile in Glacial Till. In Proc. 6th Int. Conf. Behavior of Offshore Structures (Patel, M. H. et al., (eds)). Imperial College, pp. 555-566: BPP Technical Services

Lehane, B. M. \& Jardine, R. J. (1992b). The behaviour of a displacement pile in Bothkennar clay. In Proc. Wroth Memorial Symp. on Predictive Soil Mechanics (Houlsby, G. T. et al., (eds)). Oxford, UK, pp. 421-435: Thomas Telford

Lehane, B. M., Jardine, R. J., Bond, A. J. \& Frank, R. (1993). Mechanisms of shaft friction in sand from instrumented pile tests. J. Geotech. Eng-ASCE, 119, No. 1, 19-35.

Leroueil, S., Demers, D., La Rochelle, P., Martel, G. \& Virely, D. (1995). Practical applications of the piezocone in Champlain sea clays. In Proc. Int. Symp. on Cone Penetration Testing, Linkoping, Sweden, pp. 515-522: Swedish Geotechnical Society

Lim, J. K. \& Lehane, B. M. (2014). Characterisation of the effects of time on the shaft friction of displacement piles in sand. Géotechnique, 64, No. 6, 476-485.

Lord, J. A., Clayton, C. R. I. \& Mortimore, R. N. 2002. Report C574: Engineering in chalk, London, UK: CIRIA.

Mesri, G., Feng, T. W. \& Benak, J. M. (1990). Post densification penetration resistance of clean sands. J. Geotech. Eng., 116, No. 7, 1095-1115.

Mortimore, R. N. (2012). The 11th Glossop Lecture: Making sense of Chalk: a total-rock approach to its Engineering Geology. Q. J. Eng. Geol. Hydrogeol., 252-334

Muir Wood, A., Mackenzie, B., Burbury, D., Rattley, M., Clayton, C. R. I., Mygind, M., Wessel Andersen, K., Le Blanc Thilsted, C. \& Albjerg Liingaard, M. (2015). Design of large diameter monopiles in chalk at Westermost Rough offshore wind farm. In Poc. Conf. Frontiers in Offshore Geotechnics III (ISFOG) (Meyer, V., (ed)). Oslo, Norway, pp. 723-728: CRC Press

Norrie, C. (2015). Pile driving performance in low to medium density chalk. MSc Thesis, Imperial College London, London, UK

Novak, M., Aboul-Ella, F. \& Nogami, T. (1978). Dynamic soil reactions for plane strain case. J. Eng. Mech. Div., 104, No. EM4, 953-959.

Poulos, H. G. (1988). Cyclic stability diagram for axially loaded piles. J. Geotech. Geoenviron. Eng., 114, No. 8, 877-895.

Power, P. (1982). The use of the electric static cone penetrometer in the determination of the engineering properties of chalk. In Proc. 2nd Eur. Symp. on Penetration Testing (Verruijt, A. et al., (eds)). Amsterdam, The Netherlands, pp. 769-774: CRC Press

Randolph, M., Dolwin, J. \& Beck, R. (1994). Design of driven piles in sand. Geotechnique, 44, No. 3, 427-48.

Randolph, M. F. \& Simons, H. A. (1986). An improved soil model for one-dimensional pile driving analysis. In Proc. 3rd. Int. Conf. on Num. Meth. in Offshore Piling (Du Petrole, F., (ed)). Nantes, France, pp. 3-17: Editions Technip

Randolph, M. F. (2004). Characterisation of soft sediments for offshore applications. In Proc. 2nd Int. Conf. on Site Characterisation (Da Fonseca, V. et al., (eds)). Porto, Portugal, pp. 209-232: IOS Press

Randolph, M. F. (2008). IMPACT - Dynamic analysis of pile driving., Manual.

Razoaki, R. N. (2000). Effect of ageing on mechanics of chalk slurries. PhD Thesis, University of Portsmouth, Portsmouth, UK

Rimoy, S. P., Jardine, R. J. \& Standing, J. R. (2013). Displacement response to axial cycling of piles driven in sand. Proc. of the ICE Geotech. Eng., 166, No. GE2, 131-146.

Rimoy, S. P., Silva, M., Jardine, R. J., Yang, Z. X., Zhu, B. T. \& Tsuha, C. H. C. (2015). Field and model investigations into the influence of age on axial capacity of displacement piles in silica sands. Géotechnique, 65, No. 7, 576-589.

Salgado, R., Loukidis, D., Abou-Jaoude, G. \& Zhang, Y. (2015). The role of soil stiffness non-linearity in 1D pile driving simulations. Géotechnique, 65, №. 3, 169-187. 
Setech (2007). Trial site investigation - Thanet offshore wind farm trial site, 8564/1.

Skov, R. \& Denver, H. (1988). Time-dependence of bearing capacity of piles. In Proc. 3rd Int. Conf. on the Application of Stress-Wave Theory to Piles (Niyama, S. et al., (eds)). Ottowa, Canada., pp. 879-888: Balkema

Suzuki, Y. (2014). Investigation and interpretation of cone penetration rate effects. PhD Thesis, The University of Western Australia, Crawley, Australia

Tan, S. L., Cuthbertson, J. \& Kimmerling, R. E. (2004). Prediction of pile set-up in non-cohesive soils. Current practices and future trends in deep foundations - ASCE, GSP, No. 125, 50-65.

Tsuha, C. H. C., Foray, P. Y., Jardine, R. J., Yang, Z. X., Silva, M. \& Rimoy, S. (2012). Behaviour of displacement piles in sand under cyclic axial loading. Soils Found., 52, No. 3, 393-410.

Vijayvergiya, V. N., Cheng, A. P. \& Kolk, H. J. (1977). Design and installation of piles in chalk. In Proc. 9th Offshore Technology Conf., Houston, Texas, pp. 459-464: Offshore Technology Conference

White, D. J. (2005). A general framework for shaft resistance on displacement piles in sand. In Proc. Conf. Frontiers in Offshore Geotechnics I (ISFOG) (Gourvenec, S. et al., (eds)). Perth, Australia, pp. 697-703: CRC Press

Yang, Z. X., Guo, W. B., Jardine, R. J. \& Chow, F. C. (2016). Design method reliability assessment from an extended database of axial load tests on piles driven in sand. Can. Geotech. J., 54, No. 1, 59-74.

Ziogos, A., Brown, M., Ivanovic, A. \& Morgan, N. (2016). Chalk-steel interface testing for marine energy foundations. Proc. of the ICE Geotech. Eng. DOI: 10.1680/jgeen.16.00112. 0, 1-14 
Table 1 Summary of classification and index tests from 0 to $7 \mathrm{~m}$ depth (Setech, 2007, Fugro, 2012)

Table 2 Summary of pile test codes and test histories for ageing trends

Table 3 Summary of pile test codes and test histories for cyclic loading effects

Table 4 Post ageing and end of driving capacities of virgin piles in the static capacity study

Table 5 Summary of cyclic loading test outcomes

\section{LIST OF FIGURES}

Fig. 1 a) overall location of previous JIP site and current IC site b) plan showing layout of test piles and CPTus at the IC test site

Fig. 2 Typical site profile at the IC test site

Fig. 3 Peak failure envelopes interpreted from Consolidated Drained (CD) and Consolidated Undrained (CU) triaxial tests on intact and remoulded samples (data from Fugro, 2012)

Fig. 4 Section A-A: Cone resistance with depth at the IC test site (as shown on Fig. 1)

Fig. 5 Blow counts per $250 \mathrm{~mm}$ versus average penetration depth for driven piles DP1 - DP7

Fig. 6 Profile of total EoD shaft resistance obtained by back analysis of the dynamic test results

Fig. 7 Schematic of conditions encountered during exhumation of piles DP1 and DP7

Fig. 8 Radial water content profiles with relative radial distance from the pile centre a) near and far field b) near field, normalised by pile outside radius $R$

Fig. 9 Schematic of test rig (not to scale) a) side view b) elevation

Fig. 10 Schematic illustration of cyclic loading waveform

Fig. 11 Load displacement curves from first time tension tests on DP2, DP3 and DP6.

Fig. 12 Shaft capacity growth with time for first time tension tests to failure on DP2, DP3 and DP6 and retest on DP2

Fig. 13 Global stiffness versus pile load for first time tension tests to failure on DP2, DP3 and DP6 and re-test on DP2

Fig. 14 Permanent accumulated cyclic displacement normalised by pile diameter for unfailed tests a) DP1-CY1 b) DP4-CY1 c) DP5-CY1 d) DP7-CY1 and e) retest DP4-CY2

Fig. 15 Permanent accumulated cyclic displacement normalised by pile diameter for failed tests

Fig. 16 Cyclic loading interaction diagram with number of cycles either to failure or to the end of the test if unfailed

Fig. 17 Global axial loading stiffness for tests for a) unfailed tests $f$ b) failed tests

Fig. 18 Permanent displacement accumulation with cycles for metastable/unstable tests on natural scale with power law fits and parameters shown 
Fig. 19 Cyclic interaction charts showing accumulated displacements (normalised by pile diameter) at a) $\mathrm{N}=3 \mathrm{~b}$ ) $N=10$ c) $N=20$ d) $N=100$ e) $N=300$ and f) $N=60$

Fig. 20 Undrained triaxial tests on remoulded samples a) stress paths in q-p' space b) q-عax

Fig. 21 Drained triaxial tests on intact samples

Fig. 22 Signal matching results for pile DP7 a) force and velocity times impedance b) pile head displacement 
Table 1 Summary of classification and index tests from 0 to $7 \mathrm{~m}$ depth (Setech, 2007, Fugro, 2012)

\begin{tabular}{|c|c|}
\hline Test type & Range (Mean) \\
\hline Intact dry density, IDD $\left(\mathrm{Mg} / \mathrm{m}^{3}\right)$ & $1.38-1.64(1.49)$ \\
\hline Natural moisture content, $\mathrm{w}_{\mathrm{c}}(\%)$ & $28-33(29.9)$ \\
\hline Degree of saturation, $\mathrm{S}_{\mathrm{r}}(\%)$ & $90-100$ \\
\hline Liquid limit, $\mathrm{w}_{\mathrm{l}}(\%)$ & $30-31(30.6)$ \\
\hline Plasticity index, $\mathrm{I}_{\mathrm{p}}(\%)$ & $5-8(6.4)$ \\
\hline Unconfined compressive $\mathrm{strength}, \mathrm{q}_{\mathrm{u}}(\mathrm{MPa})$ & 2.1 \\
\hline Particle density, $\mathrm{G}_{\mathrm{s}}\left(\mathrm{Mg} / \mathrm{m}^{3}\right)$ & 2.71 \\
\hline
\end{tabular}

Table 2 Summary of pile test codes and test histories for ageing trends

\begin{tabular}{|l|l|l|l|}
\hline \multirow{2}{*}{ Test pile } & Test code & Pile Age (days) & Comment \\
\hline \multirow{2}{*}{ DP2 } & DP2-T1 & 10 & \\
\cline { 2 - 4 } & DP2-T2 & 227 & Static test on previously untested pile \\
\hline DP3 & DP3-T1 & 106 & Static test on previously untested pile \\
\hline DP6 & DP6-T1 & 246 & Static test on previously untested pile \\
\hline
\end{tabular}

1. The test code nomenclature refers to the pile number (e.g. DP1), then the test type (CY = cyclic, $\mathrm{T}=$ first time static tension TPC = post cyclic static tension) and the number of experiments previously completed up to and including that test. 
Table 3 Summary of pile test codes and test histories for cyclic loading effects

\begin{tabular}{|c|c|c|c|c|}
\hline Test pile & Test code $^{1}$ & Pile Age (days) & Mode & Comment \\
\hline \multirow{3}{*}{ DP1 } & DP1-CY1 & 253 & Cyclic & Low level cyclic test on previously untested pile \\
\hline & DP1-CY2 & 253 & Cyclic & Second cyclic test immediately after DP1-CY1 \\
\hline & DP1-TPC & 253 & Static & 'Quick' static test post cyclic failure \\
\hline \multirow{3}{*}{ DP4 } & DP4-CY1 & 249 & Cyclic & Low level cyclic test on previously untested pile \\
\hline & DP4- TPC & 249 & Static & 'Quick' static test post DP4-CY1 \\
\hline & DP4-CY2 & 255 & Cyclic & Second cyclic test on DP4 (Retest) \\
\hline \multirow{3}{*}{ DP5 } & DP5-CY1 & 254 & Cyclic & Low level cyclic test on previously untested pile \\
\hline & DP5-CY2 & 254 & Cyclic & Second cyclic test immediately after DP5-CY1 \\
\hline & DP5-TPC & 254 & Static & 'Quick' static test post cyclic failure \\
\hline \multirow{2}{*}{ DP7 } & DP7-CY1 & 247 & Cyclic & Cyclic test on previously untested pile \\
\hline & DP7- TPC & 247 & Static & 'Quick' static test post cyclic failure \\
\hline
\end{tabular}

and the number of experiments previously completed up to and including that test.

Table 4 Post ageing and end of driving capacities of virgin piles in the static capacity study

\begin{tabular}{|c|c|c|c|c|}
\hline Test code & Age (days) & Shaft Capacity ${ }^{\mathbf{1}}(\mathbf{k N})$ & Shaft Resistance $\left.{ }^{\mathbf{2}} \mathbf{k P a}\right)$ & ${\text { Capacity } \text { Change }^{\mathbf{3}} \mathbf{( \% )}}$ \\
\hline DP2-T1 & 10 & 94 & 39 & +239 \\
\hline DP3-T1 & 106 & 186 & 77 & +473 \\
\hline DP6-T1 & 246 & 206 & 86 & +524 \\
\hline
\end{tabular}

1. Includes correction for pile and soil self weight

2. External - only external shaft resistance is assumed to be mobilised during a static tension test

3. Calculated based on average external compressive shaft capacity from three DLT results $(=39.3 \mathrm{kN})$ 
Table 5 Summary of cyclic loading test outcomes

\begin{tabular}{|c|c|c|c|c|c|c|c|c|c|c|c|}
\hline \multirow[b]{2}{*}{ Test code } & \multirow[b]{2}{*}{$\begin{array}{l}Q_{\min } \\
(\mathbf{k N})\end{array}$} & \multicolumn{8}{|c|}{ One way axial cyclic loading } & \multicolumn{2}{|c|}{$\begin{array}{l}\text { Post cyclic axial } \\
\text { tension loading }\end{array}$} \\
\hline & & $\begin{array}{l}Q_{\max } \\
(\mathbf{k N})\end{array}$ & $\begin{array}{c}Q_{t} \\
(k N)^{1}\end{array}$ & $\begin{array}{c}Q_{c y c} / Q_{t} \\
(-)\end{array}$ & $\begin{array}{c}\mathbf{Q}_{\text {mean }} / Q_{t} \\
(-)\end{array}$ & $\begin{array}{l}U^{2} \\
(-)\end{array}$ & $\begin{array}{l}\text { Period } \\
\text { T (s) }\end{array}$ & $\begin{array}{c}\text { No. of } \\
\text { cycles }^{3}\end{array}$ & Class & $\begin{array}{c}Q_{p c} \\
(k N)\end{array}$ & $\begin{array}{c}\text { Capacity } \\
\text { change } \\
(\%)^{4}\end{array}$ \\
\hline $\mathrm{DP} 1-\mathrm{CY} 1^{5}$ & 40 & 103 & 207.6 & 0.15 & 0.34 & 0.50 & 15 & $>1059$ & MS/S & - & - \\
\hline DP1-CY2 & 40 & 164 & 207.6 & 0.30 & 0.49 & 0.79 & 30 & 5 & US & 117.6 & -43 \\
\hline DP4-CY1 & 82 & 145 & 207.4 & 0.15 & 0.55 & 0.70 & 15 & $>1004$ & MS/S & 216.8 & +5 \\
\hline $\mathrm{DP} 4-\mathrm{CY} 2^{5}$ & 49 & 146 & 207.8 & 0.23 & 0.47 & 0.70 & $20-30$ & $>1003$ & $\mathrm{~S}$ & - & - \\
\hline DP5-CY1 & 4 & 99 & 207.7 & 0.23 & 0.25 & 0.48 & 15 & $>1000$ & $\mathrm{MS} / \mathrm{S}$ & - & - \\
\hline DP5-CY2 & 5 & 146 & 207.7 & 0.34 & 0.36 & 0.70 & 30 & 32 & US & 158.4 & -24 \\
\hline DP7-CY1 & 24 & 120 & 207.3 & 0.23 & 0.35 & 0.58 & 30 & $>1000$ & $\mathrm{MS} / \mathrm{S}$ & 177.9 & -14 \\
\hline
\end{tabular}

1. Reference capacity $Q_{t}$ at the time of the test calculated from Eq. 2 .

$\mathrm{UR}=$ Utilisation Ratio $=\mathrm{Q}_{\max } / \mathrm{Q}_{\mathrm{t}}$

prefix " $>$ " : no cyclic failure when number of cycles reached

When compared to $Q$

Marginally higher cyclic loads were applied initially than intended for three cycles; these have not been included in the cycle number or

permanent displacement trends

6. Re-test on a pile previously failed in static tension and subjected to cyclic loading

7. All loads given in Table are net loads (measured load less pile and chalk self weight) 


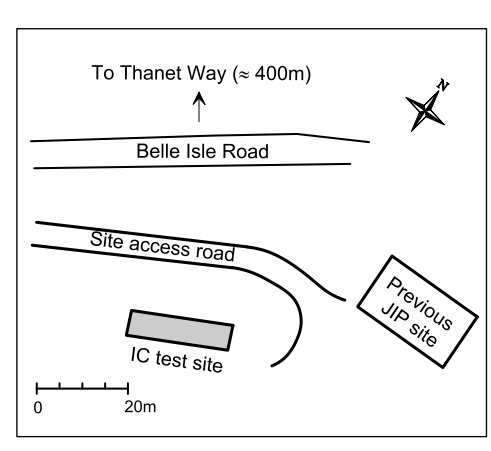

(a)

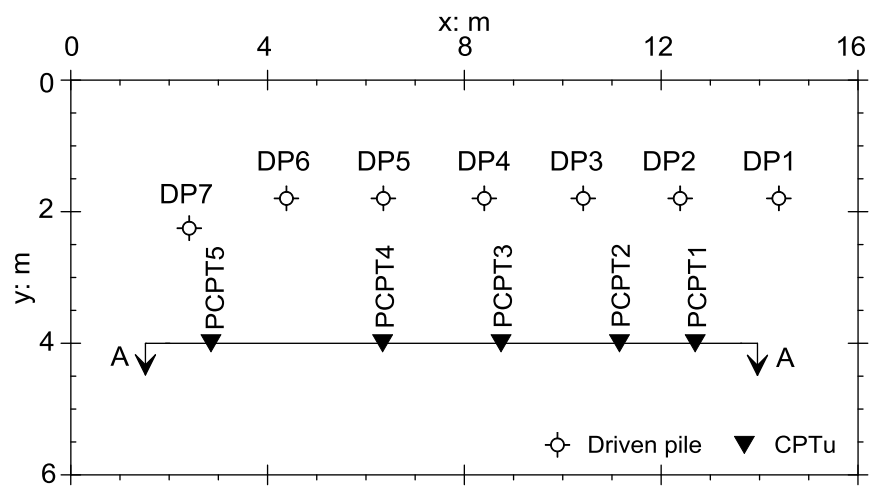

(b)

Figure 1 a) overall location of previous JIP site and current IC site b) plan showing layout of test piles and CPTus at the IC test site

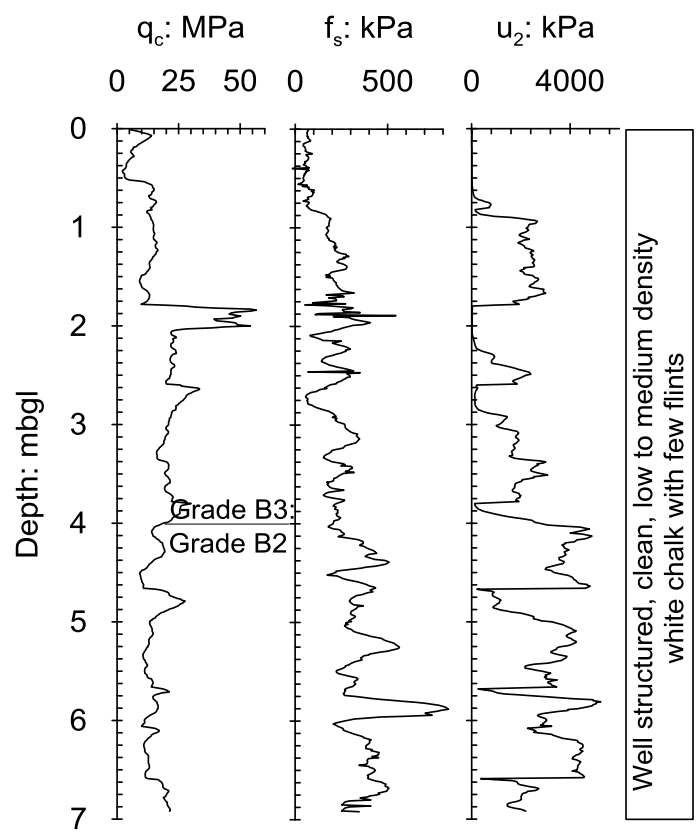

Figure 2 Typical site profile at the IC test site 


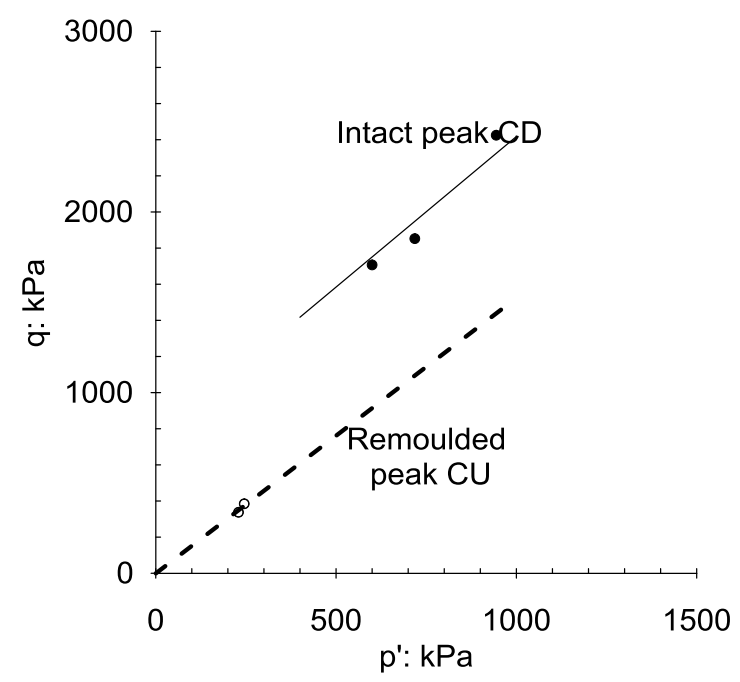

Figure 3 Peak failure envelopes interpreted from Consolidated Drained (CD) and Consolidated Undrained (CU) triaxial tests on intact and remoulded samples (data from Fugro, 2012)

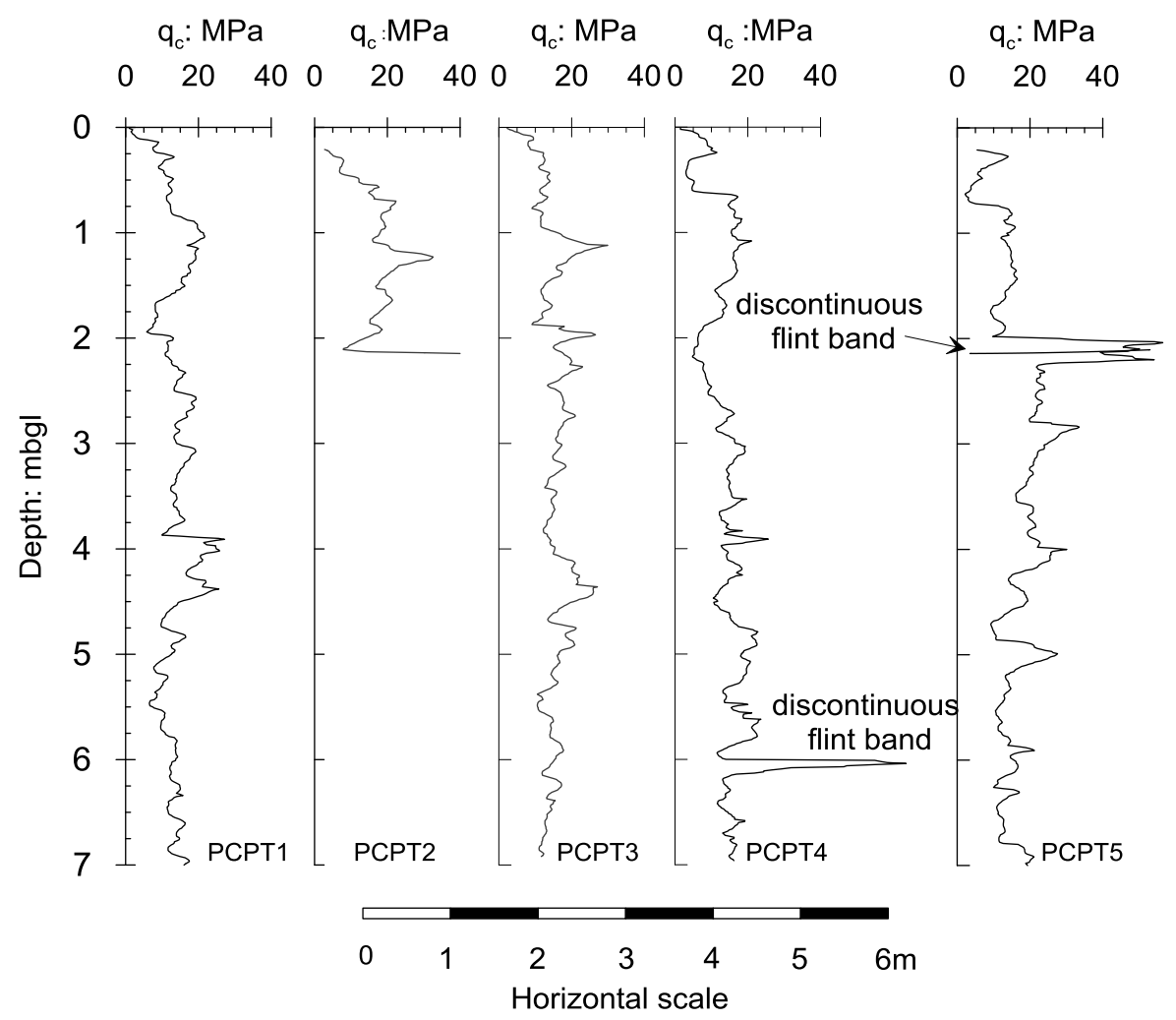

Figure 4 Section A-A: Cone resistance with depth at the IC test site (as shown on Figure 1) 


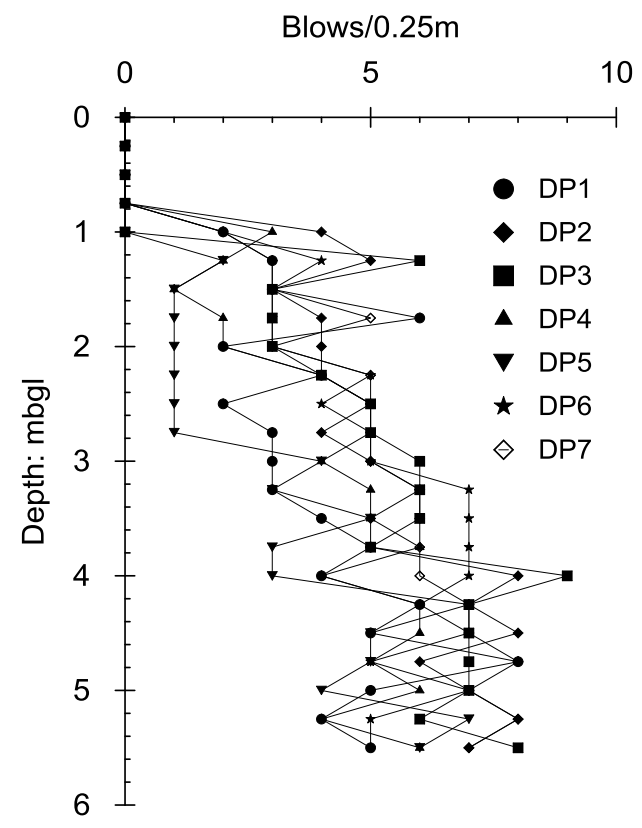

Figure 5 Blow counts per 250mm versus average penetration depth for driven piles DP1 - DP7

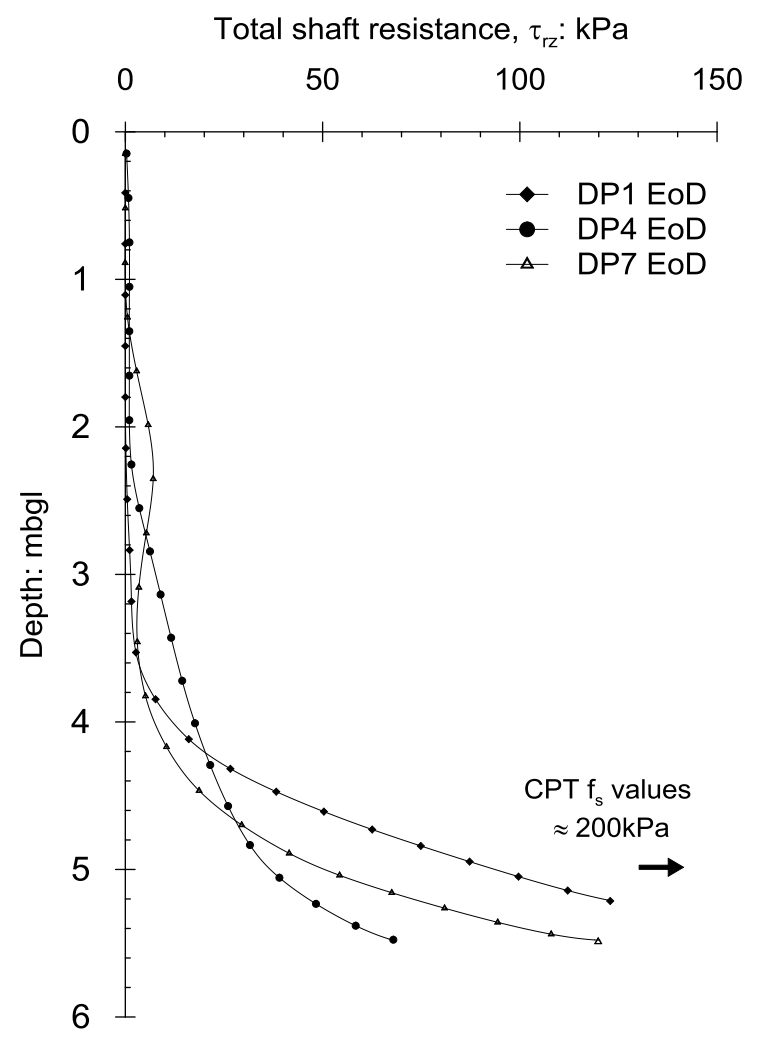

Figure 6 Profile of total EoD shaft resistance obtained by back analysis of the dynamic test results 


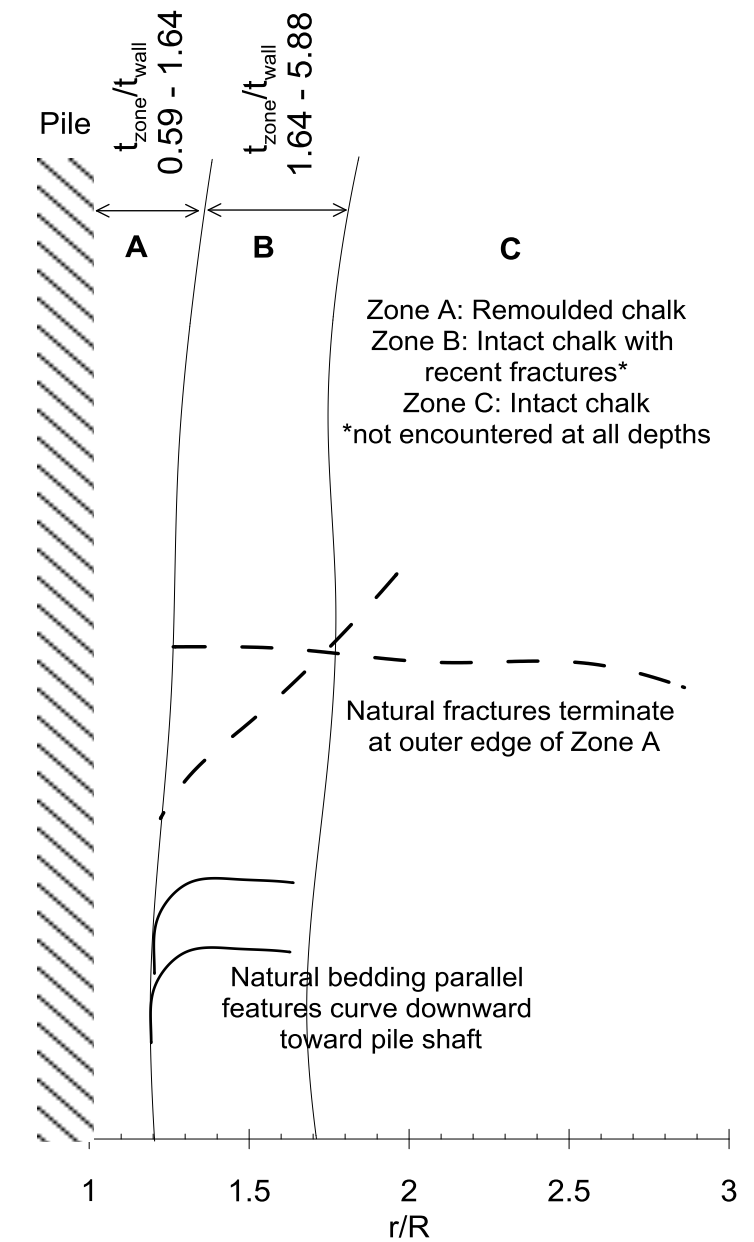

Figure 7 Schematic of conditions encountered during exhumation of piles DP1 and DP7 


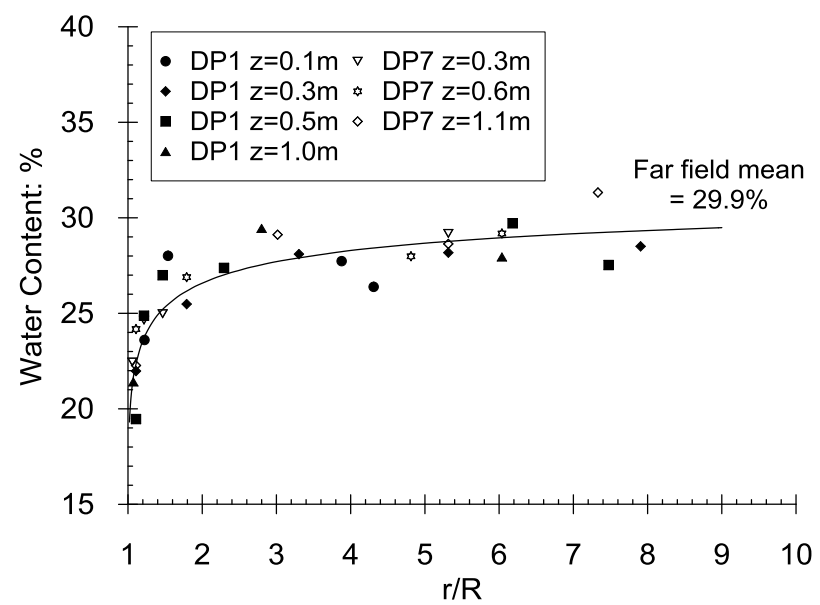

(a)

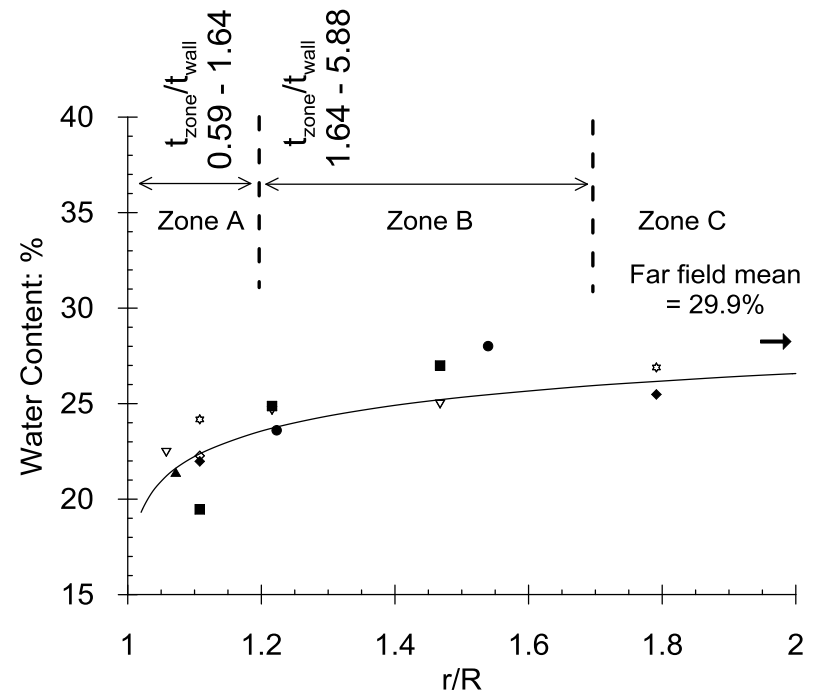

(b)

Figure 8 Radial water content profiles with relative radial distance from the pile centre a) near and far field b) near field, normalised by pile outside radius $R$ 


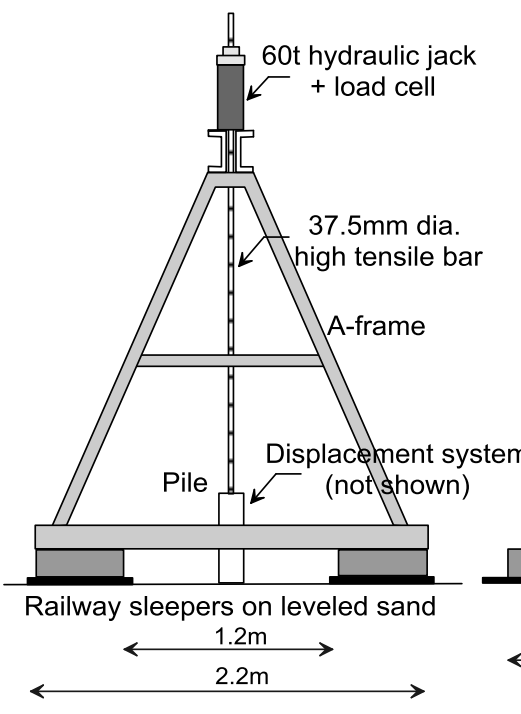

a)

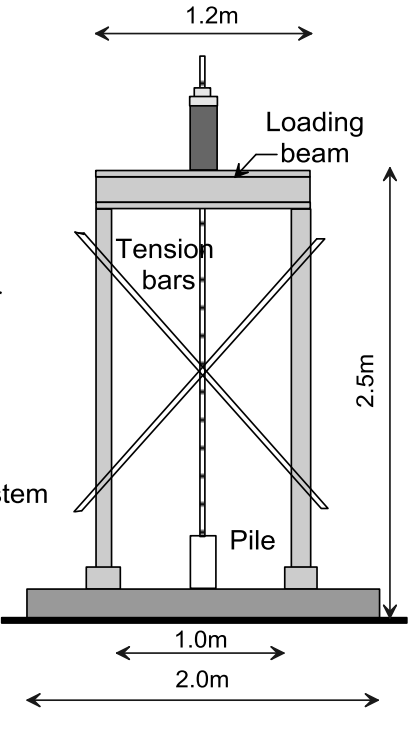

b)

Figure 9 Schematic of test rig (not to scale) a) side view b) elevation

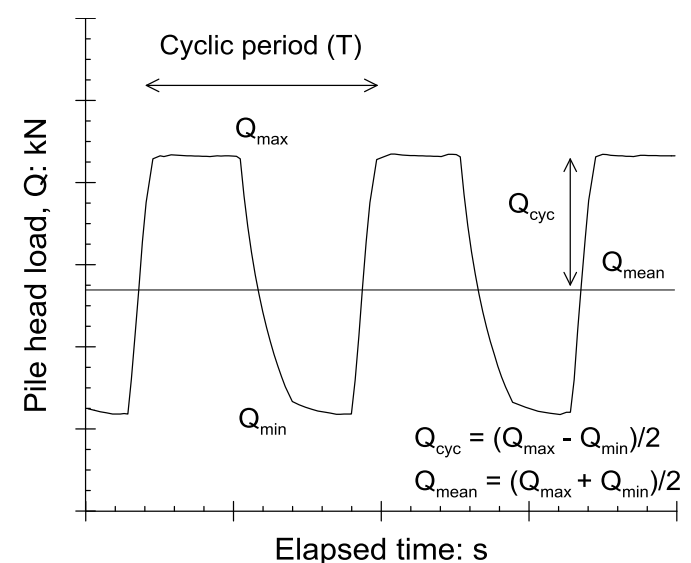

Figure 10 Schematic illustration of cyclic loading waveform 


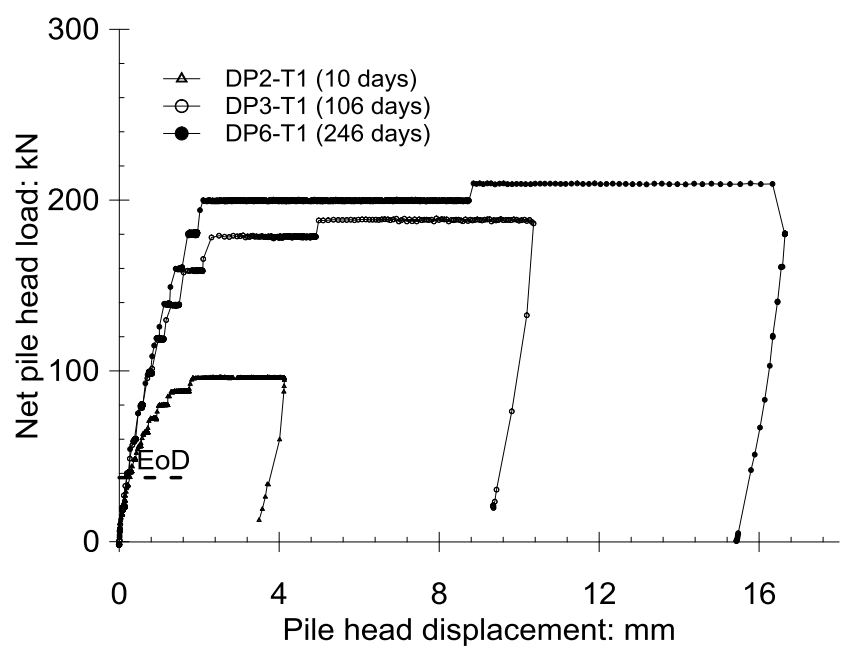

Figure 11 Load displacement curves from first time tension tests on DP2, DP3 and DP6.

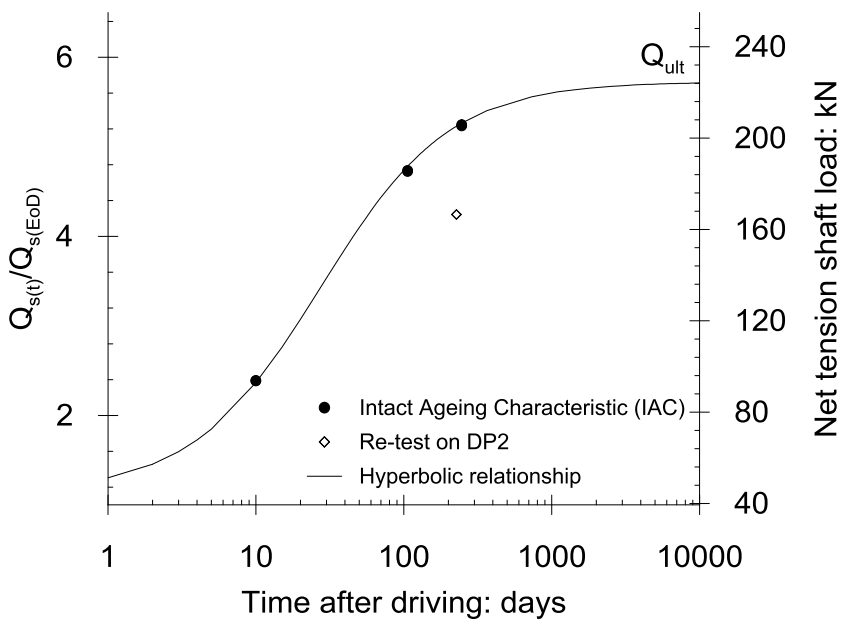

Figure 12 Shaft capacity growth with time for first time tension tests to failure on DP2, DP3 and DP6 and retest on DP2 


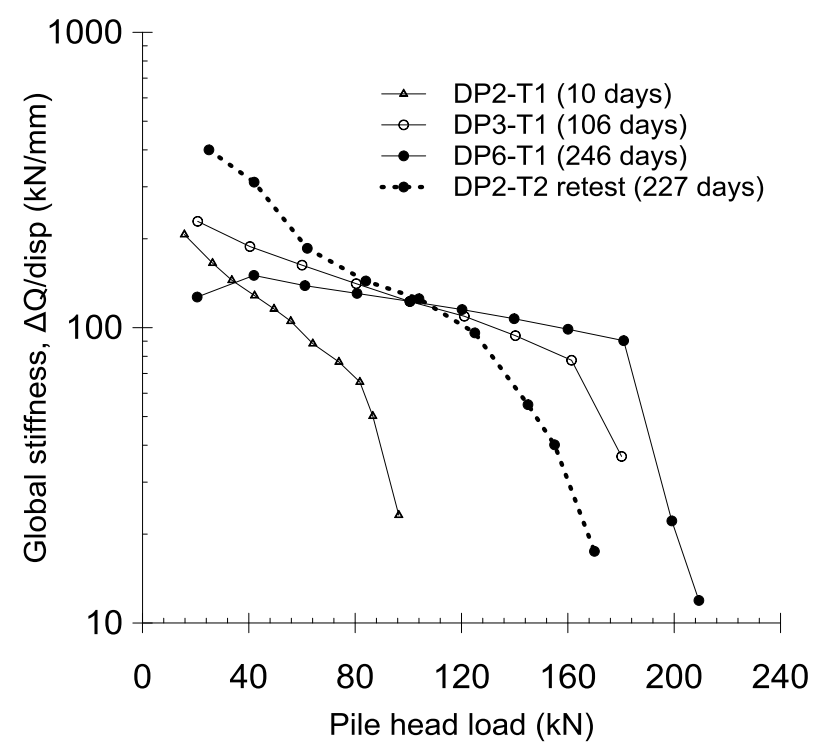

Figure 13 Global stiffness versus pile load for first time tension tests to failure on DP2, DP3 and DP6 and re-test on DP2 


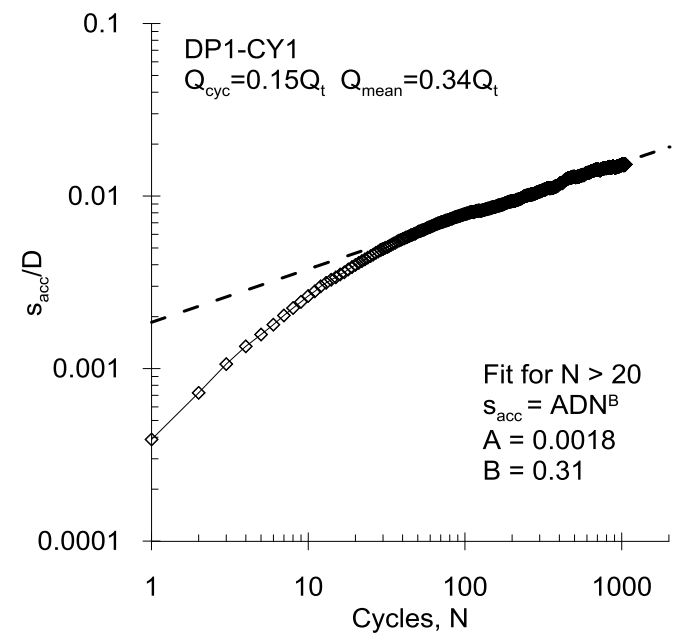

(a)

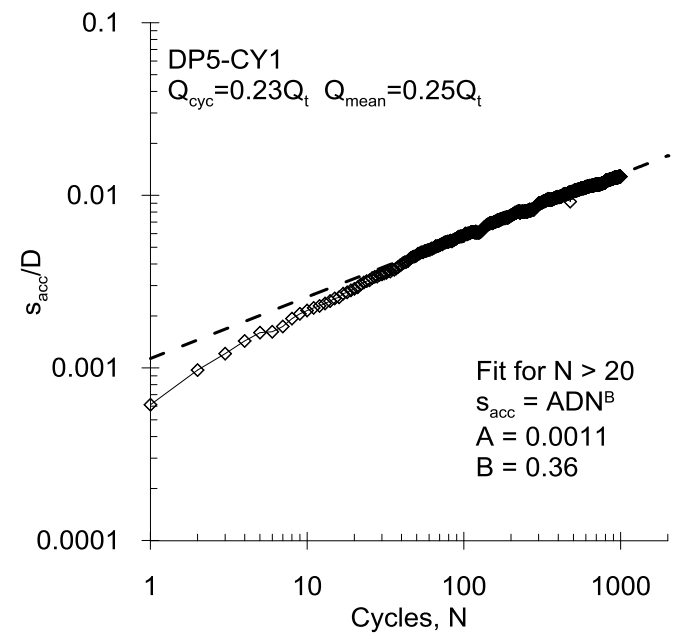

(c)

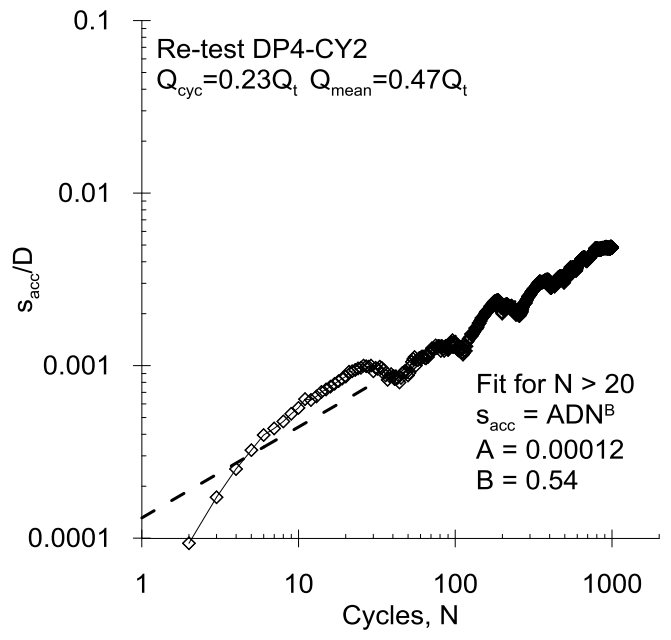

(e)

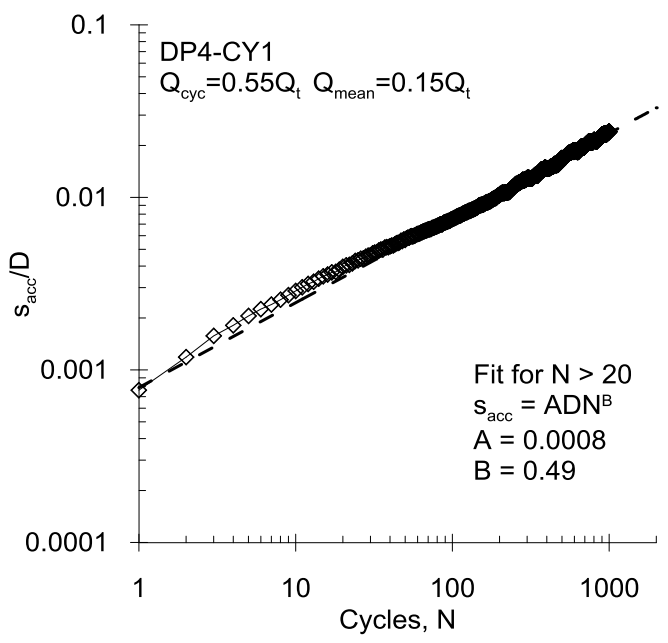

(b)

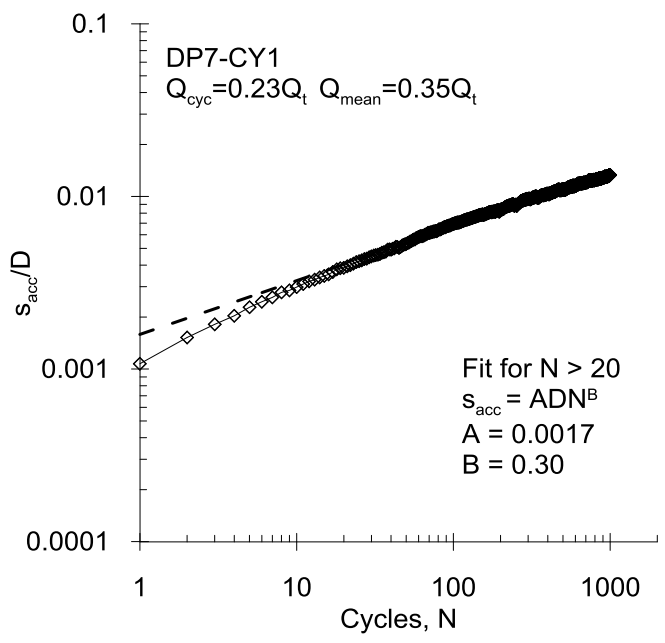

(d)

Figure 14 Permanent accumulated cyclic displacement normalised by pile diameter for unfailed tests a) DP1-CY1 b) DP4-CY1 c) DP5-CY1 d) DP7-CY1 and e) retest DP4-CY2 


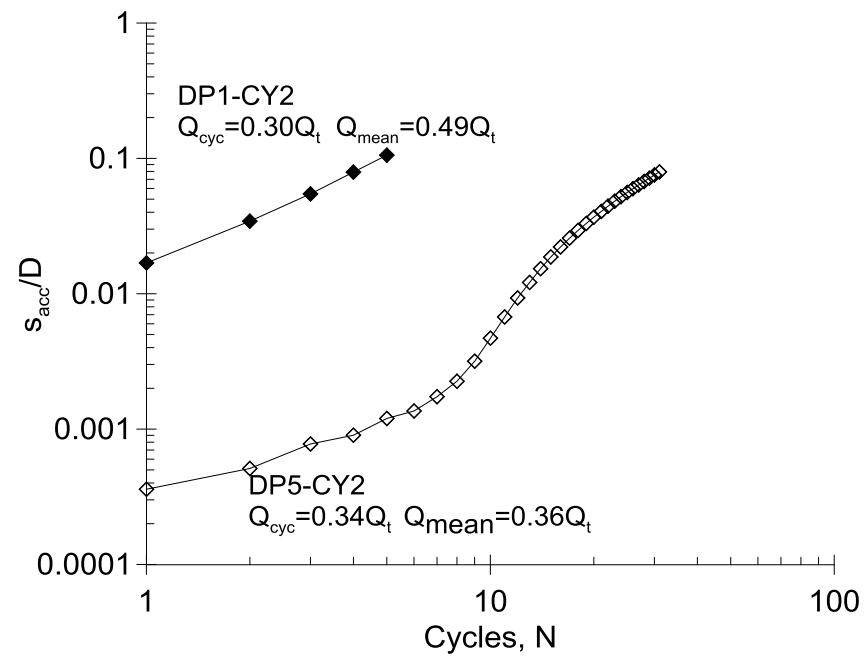

Figure 15 Permanent accumulated cyclic displacement normalised by pile diameter for failed tests

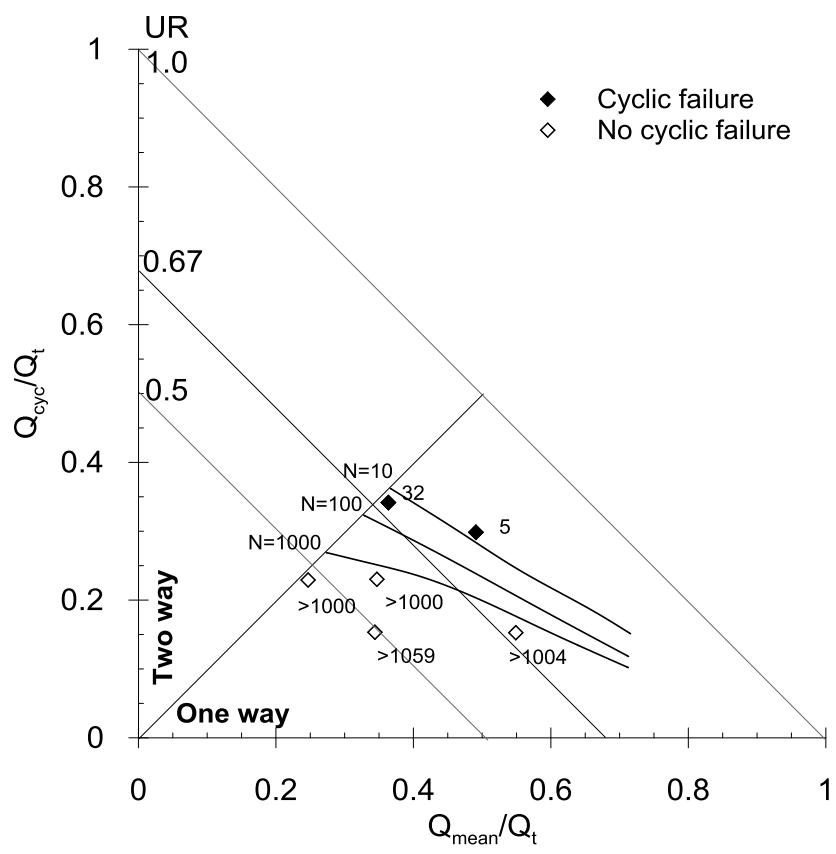

Figure 16 Cyclic loading interaction diagram with number of cycles either to failure or to the end of the test if unfailed 


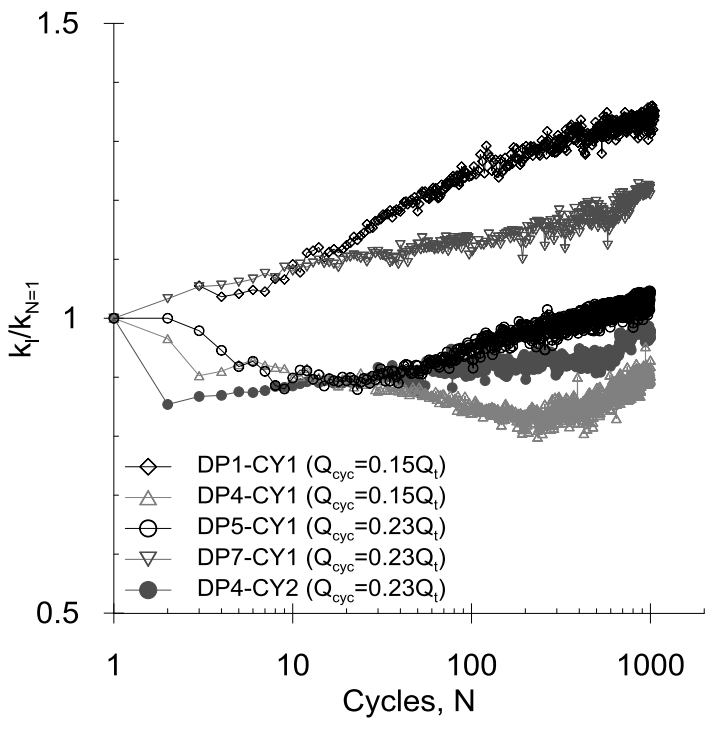

(a)

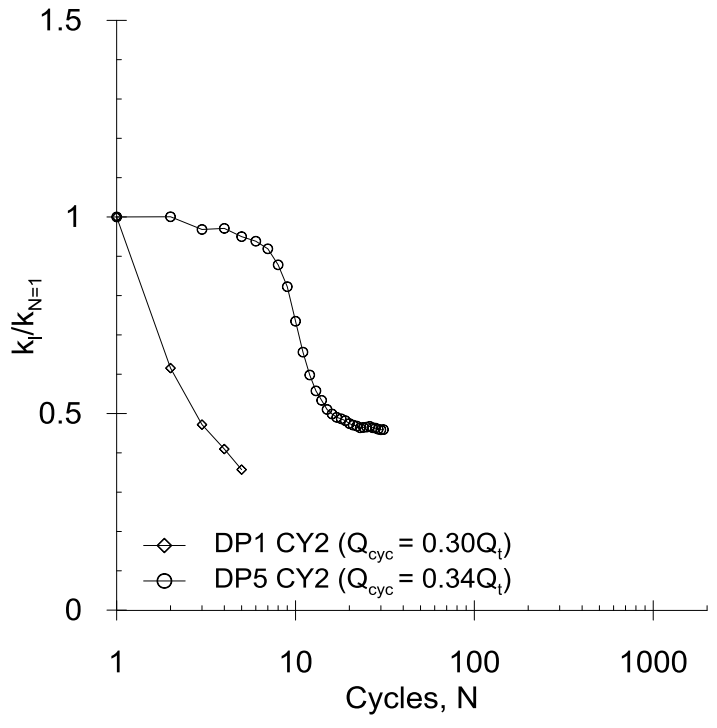

(b)

Figure 17 Global axial loading stiffness for tests for a) unfailed tests $f$ b) failed tests

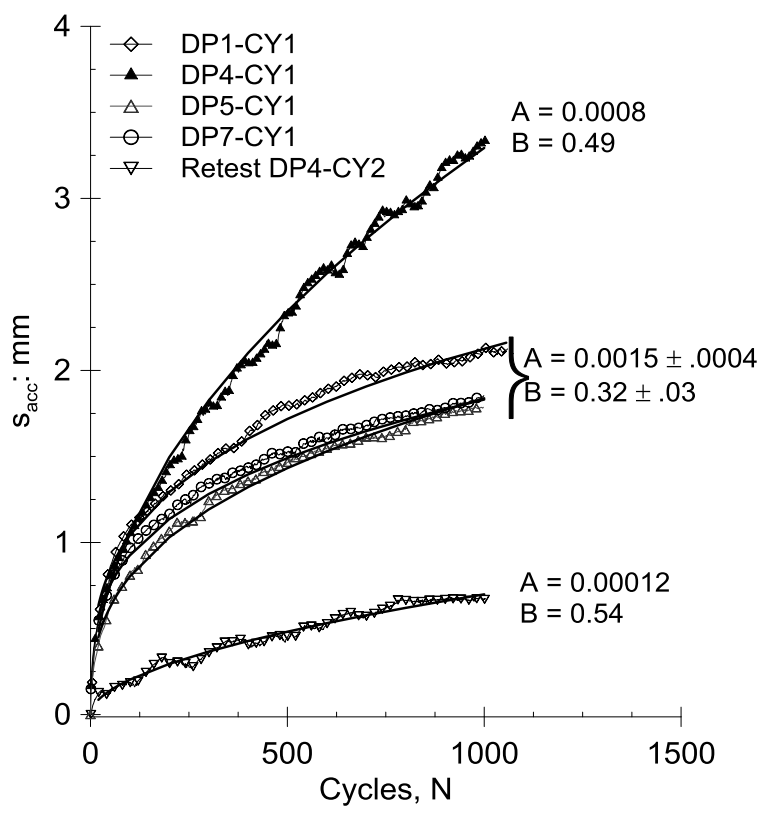

Figure 18 Permanent displacement accumulation with cycles for metastable/unstable tests on natural scale with power law fits and parameters shown 


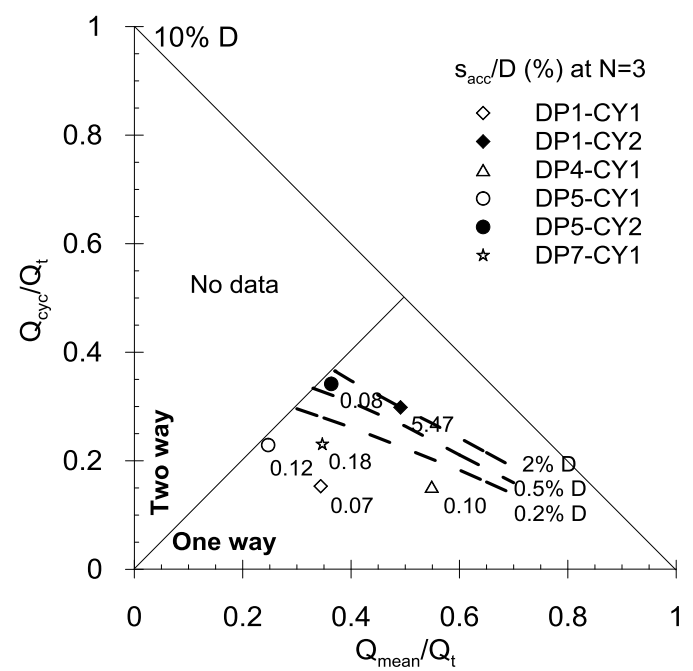

(a)

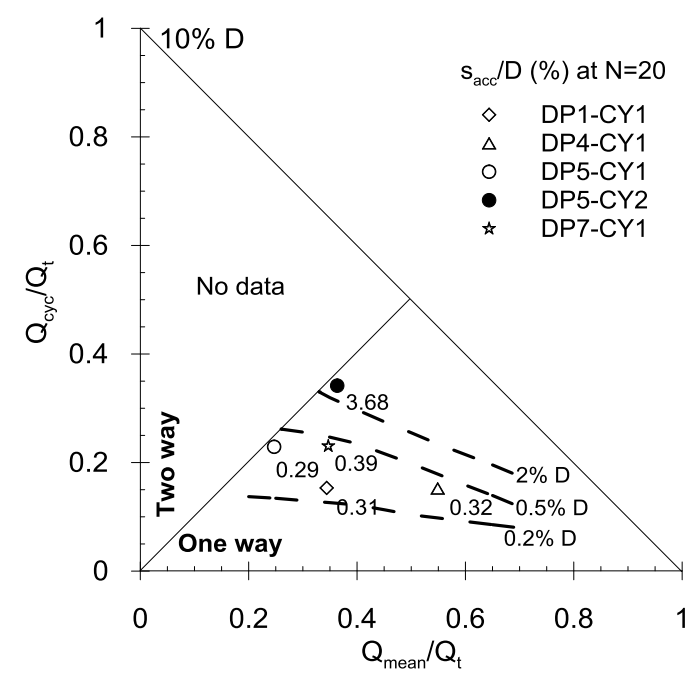

(c)

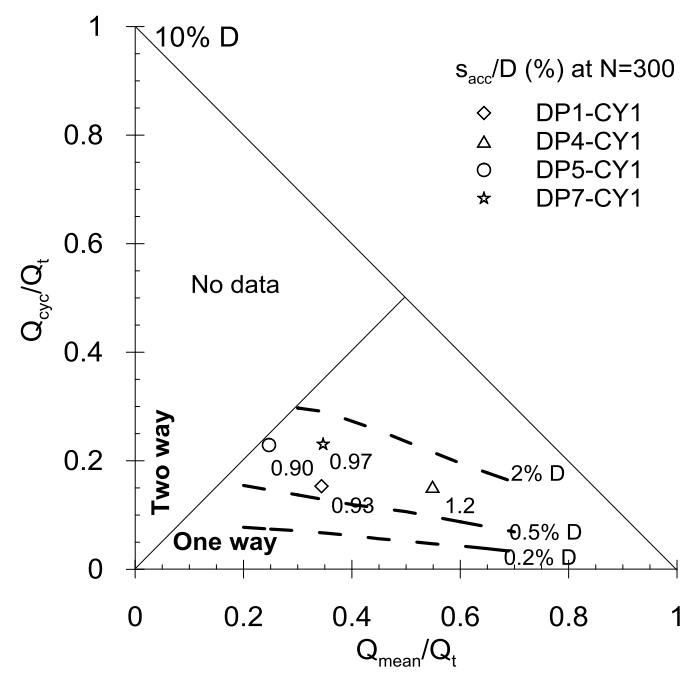

(e)

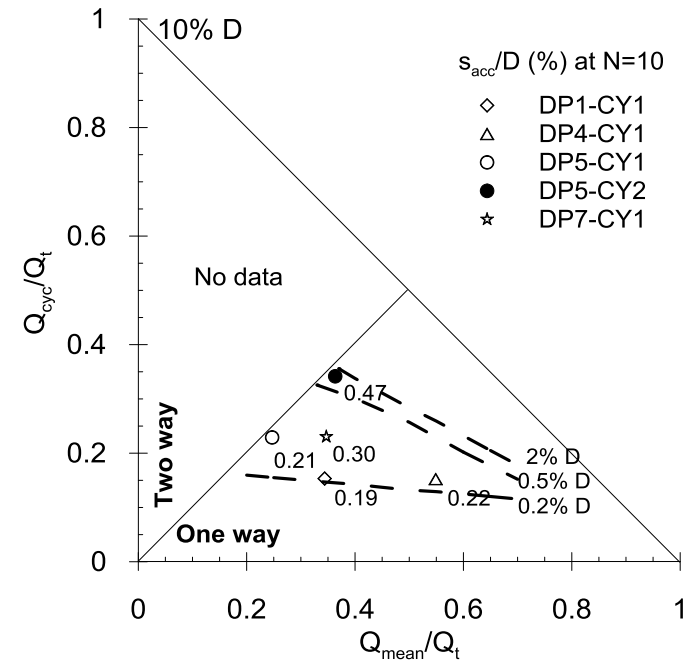

(b)

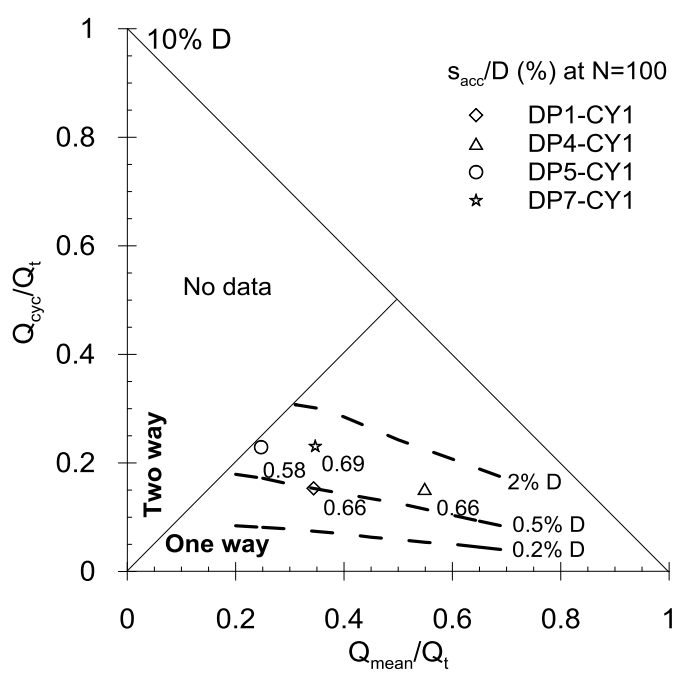

(d)

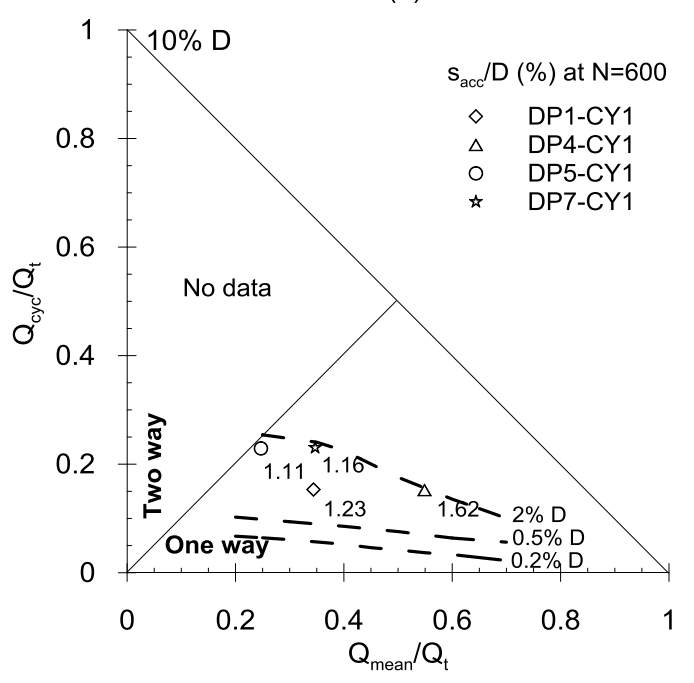

(f)

Figure 19 Cyclic interaction charts showing accumulated displacements (normalised by pile diameter) at a) $\mathrm{N}=3 \mathrm{~b}$ ) $\mathrm{N}=10$ c) $\mathrm{N}=20$ d) $\mathrm{N}=100$ e) $\mathrm{N}=300$ and f) $\mathrm{N}=60$ 

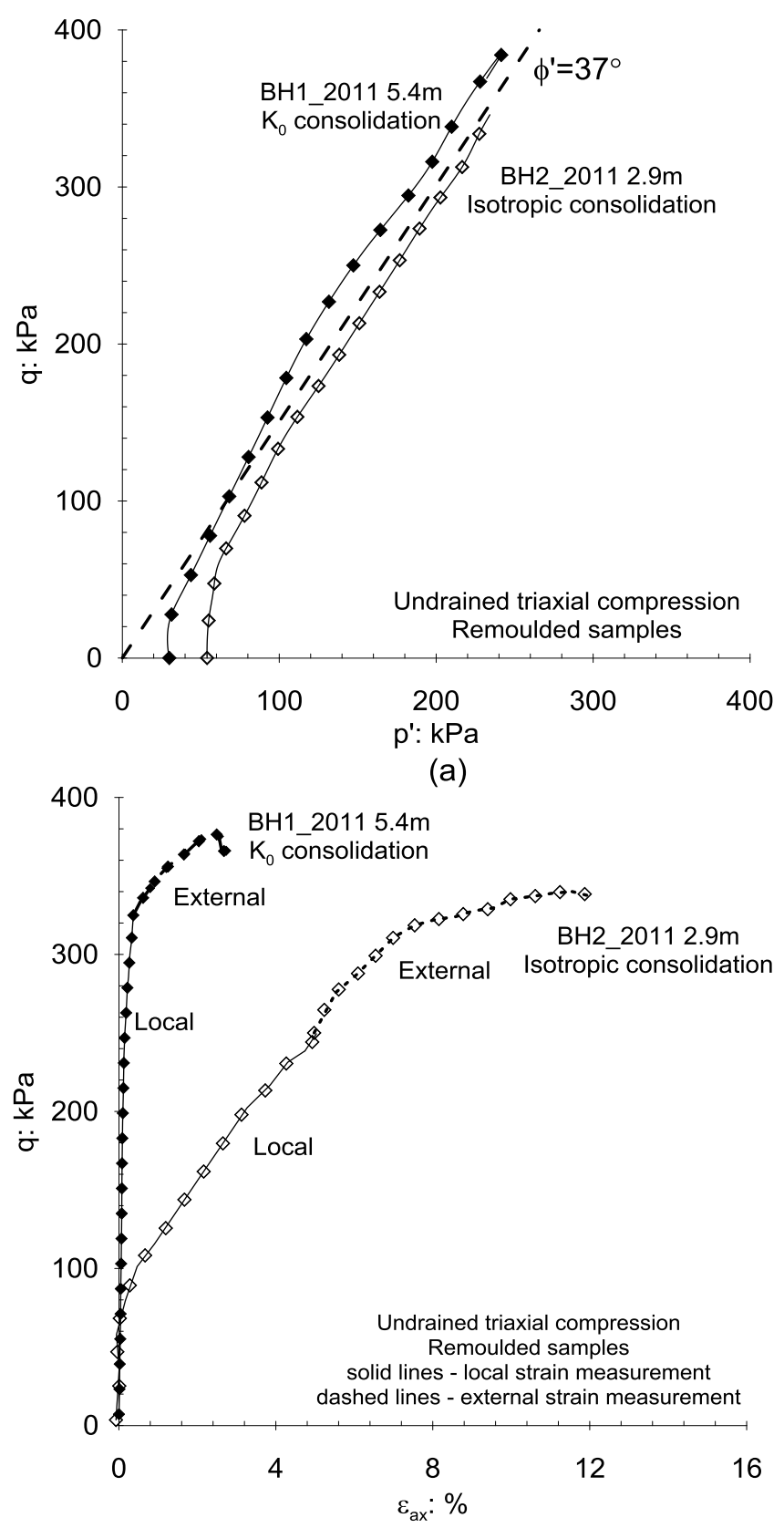

(b)

Figure 20 Undrained triaxial tests on remoulded samples a) stress paths in q-p' space b) q-Eax 


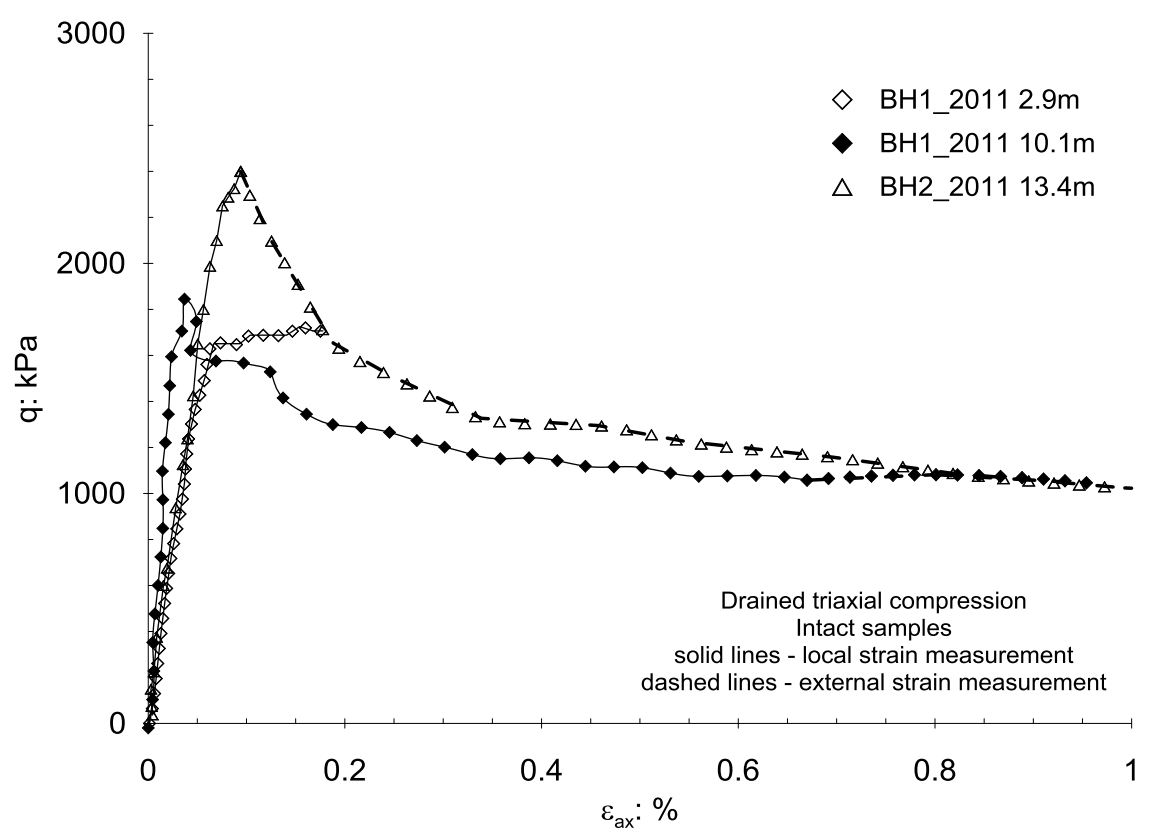

Figure 21 Drained triaxial tests on intact samples 


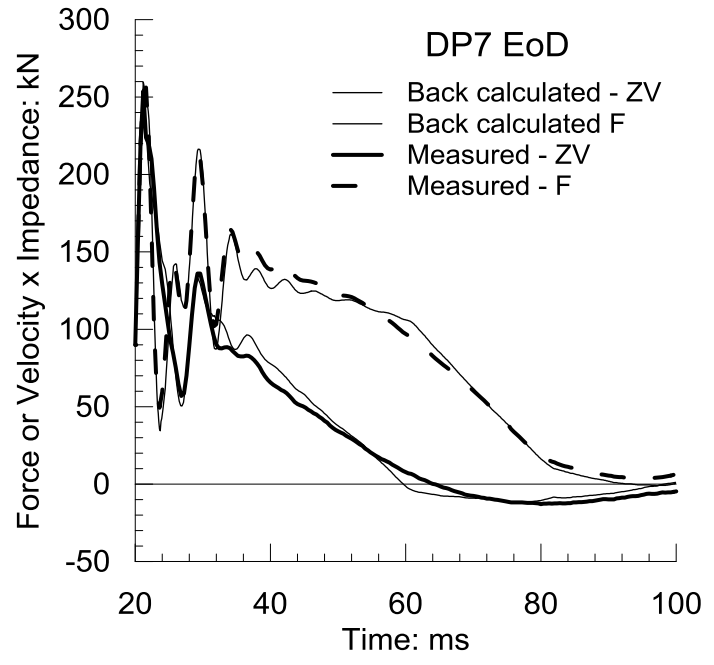

(a)

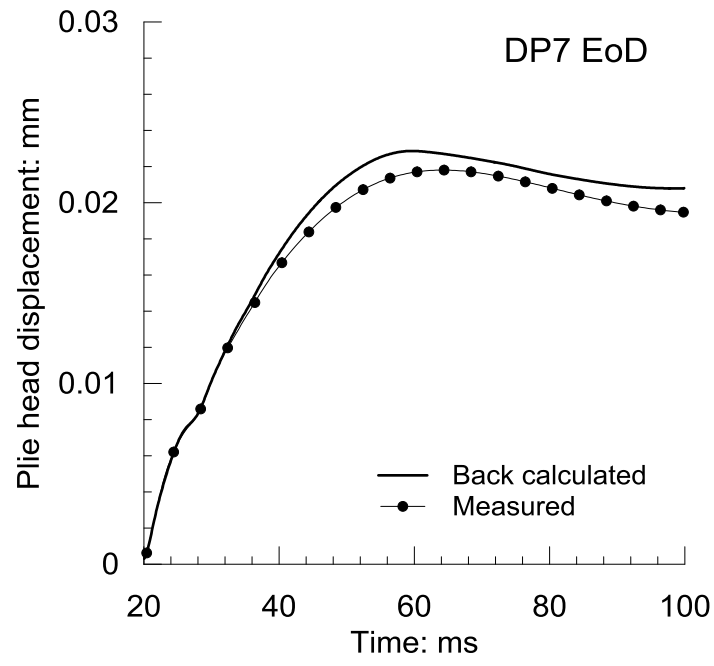

(b)

Figure 22 Signal matching results for pile DP7 a) force and velocity times impedance b) pile head displacement 